AperTO - Archivio Istituzionale Open Access dell'Università di Torino

\title{
Endogenous Cardioprotective Agents: Role in Pre and Postconditioning.
}

\section{This is a pre print version of the following article:}

Original Citation:

\section{Availability:}

This version is available http://hdl.handle.net/2318/1509282

since 2016-06-03T12:51:51Z

Published version:

DOI:10.2174/1389450116666150309115536

Terms of use:

Open Access

Anyone can freely access the full text of works made available as "Open Access". Works made available under a Creative Commons license can be used according to the terms and conditions of said license. Use of all other works requires consent of the right holder (author or publisher) if not exempted from copyright protection by the applicable law. 


\title{
Endogenous Cardioprotective Agents: Role in Pre and Postconditioning
}

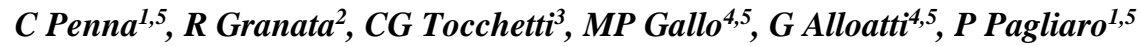 \\ ${ }^{1}$ Department of Clinical and Biological Sciences, University of Torino, Orbassano (TO), Italy; \\ ${ }^{2}$ Division of Endocrinology, Diabetes and Metabolism, Department of Medical Sciences, University of Torino, Torino, \\ Italy; \\ ${ }^{3}$ Department of Translational Medical Sciences, Federico II University, Napoli, Italy; \\ ${ }^{4}$ Department of Life Sciences and Systems Biology, University of Torino, Torino, Italy; \\ ${ }^{5}$ National Institute for Cardiovascular Researches, Bologna, Italy.
}

Running title: Endogenous Cardioprotective Agents 


\begin{abstract}
Cardiovascular diseases (CVD) are the leading cause of death and disability in the occidental countries. The major pathological consequences of CVD derive from the harmful effects of acute myocardial ischemia and following reperfusion injury. Protection of the myocardium against damaging ischemia/reperfusion injury is made possible by “conditioning protocols”. Conditioning is obtained applying a few periods of brief ischemia and reperfusion in the event of prolonged (index) ischemia that may cause myocardial infarction. Whilst the conditioning stimulus is applied before the index ischemia in ischemic pre-conditioning, it is applied after the event in post-conditioning. Pre and postconditioning stimuli can be applied in a different/remote organ (remote pre- and post-conditioning); in this case conditioning stimulus can also be applied during the index event, in the so called remote per-conditioning. All these endogenous cardioprotective strategies recruit endogenous cytoprotective agents and factors that elicit specific cardioprotective pathways. Here, we provide an overview of many of these cardioprotective factors with respect to the literature and underline their major features and signaling mechanisms. Enphasis is given to endogenous cardioprotective agents acting or not on surface receptors, including chromogranin A derivatives, ghrelin-associated peptides, growth factors and cytokines, and to microvesicles and exosomes. Moreover the cardioprotective effects of gasotransmitters nitric oxide, hydrogen sulphide and carbon monoxide are reviewed. The possible clinical translation of these knowledge for future successful therapies is briefly and critically discussed.
\end{abstract}

Key words: Cardioprotection; Chromogranin A derivatives; Exosomes; Ghrelin-associated peptides; GPCR activators; Growth factors; Ischemia/Reperfusion; Tyrosine kinase receptor activators. 


\section{Introduction}

Cardiovascular disease (CVD) is the leading cause of death and, in particular, acute myocardial infarction (AMI) remains a major cause of mortality and morbidity worldwide. The restoration of blood and oxygen to the ischemic myocardium is the only way to limit ischemia injury, but reperfusion paradoxically exacerbates the cellular damage due to ischemic insult. In recent years it has become clear that the myocardial ischemia/reperfusion (I/R) injury can be reduced by protective strategy of ischemic conditioning, which stimulated considerable research into the mechanisms of cardioprotection.

\section{Cardiac 'conditioning'}

Myocardial conditioning refers to the stimulation of intrinsic cardioprotective mechanisms by short periods of nonlethal ischemia that target lethal tissue injury caused by a longer period of ischemia (the so called index ischemia). The conditioning stimulus can be applied before (Preconditioning, PreC), during (Perconditioning, PerC), or immediately after (Postconditioning, PostC) the 'index' ischemia.

The gold standard treatment against I/R injury by which other therapies are judged is the ischemic PreC. It was described in 1986 by Murry and colleagues [1] and consists of a series of brief periods of I/R (a few minutes) performed before the infarcting ischemia (it is also called mechanical PreC). This study has shown that infarct size can be modified by triggering endogenous mechanisms of protection. PreC not only reduces all form of cell death, but also endothelial dysfunction and activation as well as neutrophil adhesion and inflammatory response. It also reduces stunning (the contractile depression which follows ischemia) and arrhythmias [2,3]. Moreover, PreC ameliorates vascular responsiveness to endothelial-dependent vasodilatation and can slow mitochondrial metabolism [2-4].

It has been shown that PreC can also be induced by exercise protocols [5]. Actually, the cardioprotection of PreC induced by mechanical manoeuvres (i.e. brief cycles of I/R) or exercise triggers the release of various molecules (e.g. adenosine, acetylcholine, opiates, bradykinin and possibly other factors treated in this review) which are responsible for the triggering of intracellular cardioprotective pathways. A similar cardioprotection can be also induced directly by the infusion of one of these endogenous agonists or other agents for few minutes; that is pharmacological PreC [6]. Importantly, protection by either ischemic, pharmacological or exercise PreC has been demonstrated in several animal species, including humans, and can be abolished by antagonists of these endogenous agents [7].

However, PreC can be useful in programmed cardio-surgery interventions. It is not useful in the patient with AMI because it must be performed prior to ischemia. Later, ischemic/mechanical PostC, which involves to subject the myocardium to cycles of brief reperfusion and ischemia (a few seconds) at the onset of reperfusion, has also shown to be protective against I/R injury [8-10]. PostC reduces: infarct size, apoptosis, post-ischemic arrhythmias, endothelialdysfunction and -activation. However, it is not clear if it can reduce myocardial stunning [11,12]. Cardioprotection by 
pharmacological PostC has also been described. It is obtained with the infusion of some of the agents able to induce PreC, but these agents must be applied very soon in reperfusion, because the first minutes of reperfusion are critically important [13].

More recently, remote ischemic PreC, $\operatorname{PerC}$ and PostC have also proved to be protective against I/R injury [14-19]. These procedures consist in subjecting a limb or organ, remote from the heart, to brief cycles (a few minutes) of ischemia and reperfusion, prior to or during cardiac ischemia and after reperfusion, respectively.

The above described ischemic conditioning protocols are potent cardioprotective interventions that decrease infarct size after relatively long periods of cardiac ischemia followed by reperfusion. In fact, though early reperfusion in AMI limits infarct size, there may still be significant myocardial cell death due to the pathophysiological mechanisms triggered by reperfusion itself, which is termed lethal reperfusion injury. Reperfusion injury occurs as a result of a number of pathophysiological mechanisms that are triggered at the time of oxygen reintroduction after an ischemic period. Before to consider the endogenous factors responsible of cardioprotection we briefly describe the general mechanism of reperfusion injury and protection.

Mechanisms underlying reperfusion injury

The most important consequence of reperfusion injury is an increase in the open probability of the mitochondrial permeability transition pore (mPTP). The opening of mPTPs leads to the loss of mitochondrial inner membrane potential, which in turn triggers various modes of cell death including necrosis, apoptosis and necro-apoptosis [20-22]. Alteration of two or more physiological mechanisms, including cellular $\mathrm{pH}$, calcium homeostasis and production of reactive oxygen and nitrogen species (ROS/RNS), are responsible for the pore opening.

Intracellular calcium homeostasis becomes dysfunctional during ischemia via injury to the sarcolemmal membrane and the sarcoplasmic reticulum, leading to an increase in cytosolic calcium. This calcium overload is further accentuated at the time of reperfusion by calcium influx through reverse mode $\mathrm{Na}^{+}-\mathrm{Ca}^{2+}$ exchange $[23,24]$, and besides to promote mitochondrial calcium overload and mPTP opening (favored by pH recovery due to $\mathrm{Na}^{+} / \mathrm{H}^{+}$-exchanger activity) has several other deleterious effects, including formation of contraction band necrosis [24].

Also ROS/RNS production is altered by ischemia and subsequently accentuated at the time of reperfusion and contribute to cause injury to the myocardium as well as to the endothelium [25]. Ischemia also triggers inflammation leading to an increase in vascular permeability in the region of the infarct, readily permitting neutrophil migration into the ischemic risk zone upon reperfusion [26]. The release of ROS and toxic substances by activated neutrophils exacerbates tissue damage induced by reperfusion $[27,28]$.

Another important pathological mechanism contributing to reperfusion injury is the "no-reflow phenomenon". Noreflow is the lack of blood flow, which is not restored to all segments of the microvasculature in the post-ischemic 
myocardium distal to site of occlusion, even after the obstruction has been treated and removed. No-reflow in the setting of patients undergoing revascularization after ST-segment-elevation AMI is a result of microvascular obstruction due to several mechanisms [29-31]. Among these are distal thromboembolism associated with revascularization of the coronary vessel and the endothelial injury occurring as a consequence of oxidative and inflammatory stress.

\section{Protective pathways and mechanisms against lethal reperfusion injury}

As previously mentioned, conditioning protocols are dependent on signaling pathways involving several factors released from ischemic tissue and acting in autocrine/paracrine fashion (Fig. 1). Many of these, with their specificity will be considered in the present review, including also PAF (platelet activating factor), TNF- $\alpha$ (tumor necrosis factoralpha), S1P (sphingosine-1-phosphate) and chromogranin A derivatives (i.e. catestatin and vasostatin), which may be counted among endogenous triggers of pre- and/or post-conditioning. These ligands may couple to G-protein-linked receptors, or tyrosine kinase receptors, or may activate directly intracellular signaling pathways, including kinases, such as protein kinase $\mathrm{C}(\mathrm{PKC})$, nitric oxide synthase (NOS), mitochondrial ATP-sensitive potassium channels (mKATP), and may promote ROS/RNS production with signaling role. For the majority, if not for all, of the endogenous ligands the final protective target of the pathways is the mitochondria, where the signaling induces protection by preventing mPTP formation, which is considered the end-effector of the protective pathway (see below).

Regardless the fact that the ligand is formed during pre- or post-conditioning procedure, it protects against reperfusion injury, which follows the index ischemia. Similar cardioprotective mechanisms and pathways are operative in the reperfusion phase. These include acidosis, ROS signaling, as well as protective signaling pathways, namely cGMP/PKG (cyclic guanosine monophosphate/Protein kinase G), RISK (Reperfusion Injury Salvage Kinase) and SAFE (Survivor Activating Factor Enhancement).

Acidosis in the initial phase of reperfusion is protective. Its protective role has been clearly demonstrated in PostC experiments and has been attributed to the direct inhibition exerted on mitochondria, where it prevents mPTP opening [32]. Also transient pre-ischemic acidosis resulted to be protective [33]. Although PreC decreases tissue acidosis and anaerobic glycolysis during the subsequent sustained ischemic period [34], it avoids fast $\mathrm{pH}$ recovery at the beginning of reperfusion [24,35]. Therefore, both in pre- and post-conditioned hearts the persistence of a slight acidosis in the initial phase of reperfusion plays a crucial role in the protection against reperfusion damage.

ROS/RNS signaling in the initial phase of reperfusion is protective. ROS/RNS are double edged swords whose protective role have been clearly demonstrated in PostC experiments and have been attributed to the direct activation of kinases, including PKC [36-38]. Also transient pre-ischemic ROS/RNS formation resulted to be protective and it seems that redox signals arise during the reperfusion phase of the brief PreC cycles of I/R [39] or during hypoxia (not anoxia) PreC [40]. Although PreC modulates ROS/RNS production during the ischemic period [34,41], it also modulates and 
limits (not avoids) ROS/RNS production during reperfusion [35,37,38,40-42]. Therefore, both in pre- and postconditioned hearts the persistence of a slight production of ROS/RNS in the initial phase of reperfusion plays a pivotal role in the protection against reperfusion injury.

The acidosis and redox signaling in early reperfusion contribute to the activation of cardioprotective pathways, which include several processes and enzyme activation/inhibition. They have been described in several excellent reviews, to which the reader is kindly redirected; see for example [3-6,10,14,16,35-38,43-47]. These pathways are here briefly described when considering the single ligand in the next section of the present review. In brief, three mainstream cardioprotective pathways are described, namely the cGMP/PKG pathway, which starts from nitric oxide formation and guanylyl cyclase (GC) activation, the RISK pathway, which includes activation of protein kinase B (PKB, also known as Akt) and extracellular signal-regulated kinase (ERK)1/2, and the SAFE pathway, which requires the activation of the signal transducer and activator of transcription 3 (STAT3). These pathways converge on the mitochondria, which are considered the intrecellular effector to limit I/R injury.

\section{Intracellular End Effectors (Mitochondria)}

Mitochondria are major common intracellular target structures in both PreC and PostC by the majority of the endogenous cardioprotective factors [12,37,47-49]. These organelles represent $40 \%$ of cardiomyocytes mass and are the site of aerobic ATP production and hence they are fundamental for energy production to sustain myocyte functions and survival. Mitochondria have also a role of paramount importance in apoptosis, autophagy and necrosis [12,37, 47-49]. Actually, the final effector of protection is likely the mPTP, and the cardioprotective signaling pathways are effective by preventing pore formation. Various protein kinases collaborate to activate the mKATP channels, thereby leading to a modest production of ROS [37,39,45]. Kinases and ROS-signaling contribute to inhibit the opening of the mPTP $[7,23,35,37,48,49]$. Also nitros(yl)ation of mitochondrial membrane proteins seems causally involved in cardioprotection by PreC and PostC [38,49-52]. Several agents act on mitochondria, including adenosine. In fact, a mitochondrial localization of adenosine $A_{2 B}$ receptor has been recently reported in cardiomyocytes, which exerts a cardioprotective role [53]. Opening of mKATP channels depends on cytosolic PKG and involves PKC $\varepsilon$ in the mitochondria, which operates the transmission of the signal from PKG to the mKATP [4,12,44,45]. It has also been suggested that mitochondrial PKG may be contained in the socalled signalosomes: discrete multimolecular complexes containing critical signaling factors, formed starting from sarcolemmal caveolae, which reach the mitochondria traveling in defined cytoplasmic systems [54]. Mitochondrial connexin 43 (CX43), located on the inner membrane, appears to be fundamental in these processes. Downregulation of CX43 mitigates both mKATP-dependent cardioprotection and ROS production [55]. Actually, the cardioprotection by the mKATP opener, diazoxide, depends on phosphorylation of CX43 by PKC [56]. This suggests some sort of reverberant signaling. In fact, PKC phosphorylates 
CX43, leading to ROS production, but ROS may cause PKC activation. Moreover very recently CX43 nitros(yl)ation has been proposed as an important modification in the regulation of mitochondrial function [57]. Nevertheless, the role (channel, scaffold or signaling molecule) exerted by mitochondrial CX43 in the protective processes is not well known yet. Interestingly, PostC with diazoxide may also promote nitros(yl)ation of several mitochondrial proteins, including putative components of mPTP [38].

Although STAT3 are transcription factors, their effects in $\mathrm{I} / \mathrm{R}$ are too fast to act as gene modulator. Actually, phosphorylated STAT3 translocates to mitochondria to modulate electron transport $[4,12,37,58]$. It also phosphorylates and, therefore, inactivates GSK3 $\beta$, a downstream target and point of convergence of RISK and SAFE pathways [58-60]. Phosphorylated STAT3 could inhibit mPTP formation. Indeed, PostC increases phosphorylation of mitochondrial STAT3 in pigs, thus improving calcium retention capacity and complex I respiratory function [61]. Upstream to STAT3 there is JAK. In fact, its inhibition avoids both mitochondrial STAT3 phosphorylation and PostC cardioprotective effect. Moreover, mitochondrial STAT3 co-immunoprecipitates with cyclophilin D, the putative target of cyclosporine A (CsA), a mPTP desensitizer [62]. Cyclosporine A inhibiting mPTP opening limits infarct size in several animal species, including mice [62] and pigs [63-64], but not in rats [65]. Also in AMI patients during primary percutaneous coronary intervention, CsA given as an intravenous bolus just before reperfusion limited infarct size, as suggested by analysis of creatine kinase release [66]. Similarly, cardioprotection by CsA was also reported for patients subjected to coronary artery bypass surgery [67]. However, because of the adverse effects and non-selectivity of CsA for the mPTP, more specific and safer novel mPTP inhibitors must be identified and developed in order to implement mPTP inhibition as a therapeutic cardioprotective strategy. Nevertheless, despite intensive investigation, the actual molecular identity of the pore component(s) of the mPTP remains unknown, thereby making difficult the research for appropriate drug(s) to target this pore.

Below we consider the endogenous cardioprotective factors, with their specificity in inducing the above described general mechanisms of protection.

\title{
Cardioprotective Agents Acting on Surface receptors \\ G protein-coupled receptors (GPCRs) activators
}

\begin{abstract}
Adenosine
Adenosine is the first factors involved in PreC. It is a purine nucleoside generated both in intracellular and extracellular compartments of the myocardium. Adenosine levels rise following to various pathophysiological stimuli, in response to moderate alteration of energy state and to diverse factors (adrenaline, NO, histamine) and signaling pathways. In
\end{abstract}


particular, adenosine is a part of a metabolic signal, released after energetic discrepancies or perturbations in the equilibrium between myocardial $\mathrm{O}_{2}$ supply and demand. By binding to adenosine receptors (ARs) 1, 2A, 2B, 3 ( $\mathrm{A}_{1} \mathrm{AR}$, $\left.A_{2 A} A R, A_{2 B} A R, A_{3} A R\right)$, adenosine improving the cellular energy balance modulates several aspect of cardiovascular function, including autonomic control of the heart, cardiac and vascular resistance to insults, cardiovascular growth and remodeling, conduction of the cardiac impulse, coronary perfusion, cronotropy and inotropy [68,69].

Adenosine has been extensively studied as a factor of cardioprotection in the I/R injury. The first step in the generation of adenosine is the conversion of ATP/ADP to AMP, carried out by the ectonucleoside triphosphate diphosphohydrolase CD39, an enzyme induced by hypoxic or ischemic conditions [70]. Indeed, $\mathrm{cd}^{-/-}$mice show a blunted increase of adenosine after myocardial ischemia [71]. The second step is the conversion of AMP to adenosine, catalyzed by the ecto-5'-nucleotidase CD73, an enzyme induced by inflammation, ischemia and hypoxia [70]. Adenosine generated during or after an ischemic insult signals through ARs is able to protect the myocardium and limit cellular injury, and is involved in pre- and PostC [69,72]. The I/R damage involves several factors, such as inflammation and innate immunity, oxidative stress, ionic and energetic disturbs. The adenosine-AR system can target all these determinants of the myocardial injury and repair [69]. Indeed, ARs are GPCRs that can activate pro-survival RISK signaling, with involvement of ERK1/2, phosphatidylinositol 3-kinase (PI3K)/Akt, PKC and downstream mKATP channels $[35,43,44,69]$. An important role for EGFR transactivation, via a MMP-dependent mechanism, in AR cardiac protection has also been postulated [73], as well as maintenance of mitochondrial function and inhibition of mPTP $[35,43,44,69]$. Interestingly, in $A_{1} R$ protection the beneficial modulation of autophagy has also been implicated [74], while the inflammatory process that takes place during the ischemia-reperfusion process may be sensitive to $\mathrm{A}_{2} \mathrm{AR}$ and $A_{3} A R[75,76]$ and not to $A_{1}$, which more directly protects the myocardium when activated before ischemia, but not in reperfusion $[69,73]$. $\mathrm{A}_{2 \mathrm{~B}} \mathrm{AR}$ cardioprotection has been linked to glycogen synthase kinase 3 beta (GSK3 $\beta$ ) and the mPTP [77], and recently to the stabilization of the circadian rhythm protein period 2(Per2) with following metabolic adaptations [69,70]. Also, adenosine binding on $\mathrm{A}_{2 \mathrm{~B}} \mathrm{AR}$ results in inhibition of mitochondrial ROS generation through ERK1/2, PI3K and NOS activation [78] and in modulation of TNF $\alpha$ and neutrophils inflammation [79]. The inflammation processes in the post-ischemic phase of reperfusion are also target of $A_{3} A R$ [80]. Interestingly, $A_{3} A R$ also targets the pre-ischemic and ischemic phase [81-83]. Thus, while $A_{1}$ and $A_{3} A R$ participate in cardioprotection in the ischemic phase, $A_{2 A}$ and $A_{2 B} A R$ involvement is important in reperfusion. Therefore, $A_{1} / A_{3} A R$ can be envisioned as crucial in PreC, with $A_{2 A} / A_{2 B} A R$ crucial in ischemic PostC [84-87]. Such phenomenon is more relevant to clinical scenario of AMI, since it is feasible in the clinical setting of reperfusion. Moreover $A_{1}, A_{2}$ and $A_{3} A R$ knockout mice could be protected by PreC, whereas $\mathrm{A}_{2 \mathrm{~B}} \mathrm{AR}$ knockout mouse could not be conditioned. Yet, there is evidence suggesting a positive interaction between $\mathrm{A}_{2 \mathrm{~A}}$ and $\mathrm{A}_{2 \mathrm{~B}} \mathrm{ARs}$ in some protocol of cardioprotection $[77,88]$. The current 
thought is that all the ARs are required and interact to produce cardioprotection: activation of $\mathrm{A}_{1}$ or $\mathrm{A}_{2 \mathrm{~A}} \mathrm{AR}$ modulates $\mathrm{A}_{2 \mathrm{~B}} \mathrm{AR}$ functionality [89-91]. Such interactivity is an actual field of study and controversy in the pharmacological modulation of cardioprotection, since the main clinical studies (AMISTAD I and II) [92,93] showed some beneficial effect of adenosine only in anterior AMI, with high dose adenosine in an early reperfusion protocol.

\section{Adipocytokines}

Adipose tissue is a metabolically active endocrine organ with different body functions (e.g. energy and feeding regulation, glucose and lipid metabolism, neuroendocrine function) which impact importantly on cardiovascular system [94]. The adipose tissue achieves these effects through the release of important chemical mediators, named adipocytokines. These include adiponectin, apelin, chemerin, leptin, nesfatin, omentin, resistin, visfatin, and interleukins, including IL6, as well as plasminogen activator inhibitor 1. Here we will consider only adiponectin and briefly apelin, for the other adipocytokines the reader is kindly redirect to specific reviews [43,95].

Adiponectin is one of the most abundant adipokines secreted not only by adipocytes, but also by cardiomyocytes [96,97]. Adiponectin presents two type of receptors expressed in cardiac cells. These receptors structurally and functionally distinct from classical GPCR, have seven transmembrane domains and are named: AdipoR 1 and AdipoR 2. In liver, skeletal muscle and endothelial cells, the activation of receptors induces activation of AMP kinase (AMPK), peroxisome-proliferator activated receptor alpha (PPAR $\alpha$ ) and p38 mitogen-activated protein kinase (MAPK) [98]. Simultaneous disruption of both AdipoR1 and AdipoR2 causes marked glucose intolerance. The activation of these receptors induces a complex signaling pathway, where probably a central role is played by the activation of AMPK/endothelial NOS (eNOS), while the multiple domain protein APPL1 (adaptor protein with phosphotyrosine binding, pleckstrin homology domains and leucine zipper motif) may be a key mediator [99]. Obesity and type 2 diabetes are correlated with the reduction of adiponectin, while high levels of adiponectin are associated with reduction of CVD [100].

The beneficial cardiovascular effects, including reduction of I/R injury, induced by adiponectin are mediated by paracrine/autocrine activation of specific receptors [101] (Fig. 2). The lack of adiponectin, during I/R injury, increases myocardial infarct size and myocardial apoptosis with reduction of contractile performance [102]. The protective effects are correlated to its ability to activate AMPK, and to reduce inflammatory and oxidative/nitrative stress, thus limiting apoptosis and promoting cell survival. In fact in the null mice for adiponectin it has been observed an augmented production of NO and superoxide anion and consequently of peroxynitrite respect to wild-type mice $[98,101,102]$. The antiapoptotic effect is associated to the formation of the metabolite S1P and it is dependent by the two adiponectin receptors [103]. In the endothelial cells the AdipoR 1 and 2 activation induces NO-dependent vasodilatation and this effect is mediated by via AMPK-mediated phosphorylation of eNOS in two sites (Ser1177 and Ser633) [104]. 
Adiponectin induces the inhibition of ROS production with an AMPc/PKA/AMPK, mechanism and limits oxidized LDL and palmitate induced apoptosis in in vitro model. Yet in the marrow-derived endothelial progenitor cells (EPCs), adiponectin stimulates survival, proliferation, migration and differentiation via PI3K/Cdc42/Rac1 signaling cascade [105,106]. Important protective effects of adiponectin are mediated by a PPAR $\gamma$ dependent mechanism leading to increased expression and secretion of adiponectin. This mechanism protects the heart from hypertrophy and from

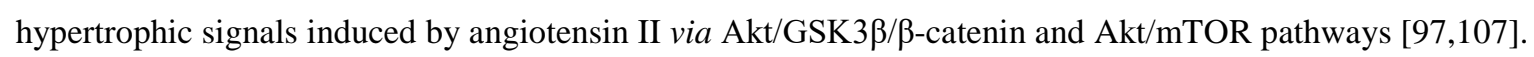

The adipocytokine, apelin, activates PI3K/Akt and ERK1/2 in various tissues and, therefore, it has been demonstrated that when administered at reperfusion at pharmacological concentrations induces cardioprotection via RISK pathway and the prevention of mPTP opening [108,109].

\section{Bradykinin}

Bradykinin (BK) is an important cardioprotective factor. BK and Lys-bradykinin (Lys-BK; kallidin) are the main kinin peptides produced by the action of serine proteases kallikrein kinin system. These two peptides are potent and efficient vasodilatatory agents, particularly active on peripheral and coronary arteries. Their vasodilator effect depends on three mechanisms: i) the release of NO, prostacyclin and endothelium derived-hyperpolarizing factor, and the inhibition of endothelin release from the endothelium, ii) inhibition of superoxide anion production and iii) inhibition of catecholamine release from the sympathetic nerve terminals in the arteries [110]. The BK effects are mediated by the activation of specific BK receptors (B1 and B2 receptors).

Several experimental models highlighted the important role of BK in cardioprotection, both in ischemic PreC and in PostC models [111-114]. In particular, Wall et al. [111] were among the first to show that the protective effect of BK is due to B2-receptors activation. In fact the antagonist of these receptors, HOE 140, blocked the effect of ischemic PreC, thus suggesting that BK was among the factors released by ischemic PreC stimuli. These results were confirmed in other animal models of conditioning, where these receptors have been shown to play a crucial role for cardioprotection [112-114]. The data regarding BK are more controversial in humans. Importantly, in a randomized study, patients undergoing isolated coronary artery bypass grafting, BK infusion prior to coronary artery bypass lowered creatinine kinase-MB release, though the troponin I levels in these patients were comparable to those measured in control group [115]. However, systemic administration of a BK B2 receptor antagonist did not affect the endothelial vasomotor dysfunction induced by I/R injury or the protection triggered by remote ischemic PreC [116].

Nevertheless, the importance of BK in clinical arena arises from the well know effect of angiotensin-converting enzyme inhibitors (ACE-I), which induce accumulation of BK. In fact some studies aiming to protect the heart obtained positive results using ACE-I alone [117,118] and other studies suggested that ACE-I may enhance the protective effects of a sub threshold conditioning stimulus [119,120]. Several large clinical trials with ACE-I have shown good out-comes with the 
administration of these drugs after AMI [121]. For instance, in several small clinical trials the ACE-I enalaprilat administered directly into the coronary artery during reperfusion improved ST-segment elevation, ventricular repolarization, arrhythmias, and inflammation, even in patients unresponsive to ischemic PreC [122]. Taken together, these data, in particular in light of its relationship with ACE system, make studies on BK particularly intriguing, deserving further investigations.

\section{Glucagon-like peptides (GLP-1 and GLP-2)}

Glucagon-like peptides 1 and 2 (GLP-1 and GLP-2) are two incretins, which comprise several gastrointestinal hormones with multiple actions, including cardioprotection. They stimulate a decrease in blood glucose levels, whose glucose-dependent insulin tropic actions have been exploited as a novel therapy for glycemic control in type 2 diabetes. Together with GIP (glucose-dependent insulinotropic peptide, also known as gastric inhibitory peptide), GLP-1 represent one of the principal incretin hormones in humans.

Glucagon-like peptide-1. GLP-1 is released from the L-cells of the small intestine and is implicated in the regulation of satiety and appetite. GLP-1 acts through GLP-1 receptor, a member of the GPCR superfamily composed of 463 aminoacids. This receptor is widely distributed in the organism. It can be find in brain, kidney, lung, pancreas, gut and stomach. The intere form of the active peptide, GLP-1 (7-36), presents metabolic effects, in particular induces glucosedependent insulin release and avoids glucagon to regulate glucose homeostasis. The enzyme dipeptidyl-peptidase- 4 swiftly catabolizes GLP-1 (7-36) to GLP-1 (9-36), which may activate GLP-1 receptor, or possibly a second unidentified receptor [123]. GLP-1(7-36) amide and the GLP-1 receptor agonist, exendin-4, induce an increase in blood pressure and heart rate in either conscious restrained or anesthetized rats, but the mechanisms are unclear [123,124]. In several models GLP-1 significantly reduced myocardial I/R injury with reduction of contracture; these protective effects were abolished by administering a GLP-1 antagonist, such as exendin (9-39), or inhibitors of PI3K [125,126]. During low flow ischemia, GLP-1 and insulin-mediated glucose uptake do not involve Akt-1 activation, but an increase in p38 MAPK activity, which is responsible for cardioprotective effect in the post-ischemic myocardium [125,127]. In fact, studies with specific inhibitors confirmed that the intracellular pathways involved in GLP-1-induced protection include p38/NO and p70s6K [126,128]. Administration of the NOS inhibitor, L-NG-Nitroarginine Methyl Ester, attenuated this protective effect in mouse model, pointing to GLP-1-mediated cardioprotection through modulation of NO. In fact, GLP-1 exerts a dose-dependent vasodilator action, which is mediated by endothelial factors, including eNOS-dependent NO release [129,130]. However, also endothelium-independent activation of KATP channels or AMP have been proposed as important mechanisms of GLP-1 vasodilator effects [131,132]. Another pathway described for GLP-1induced cardioprotection is the inactivation of the so-called endoplasmic reticulum stress signaling pathway, which comprises a decrease of both TNF receptor associated factor 2 (TRAF2) and activating transcription factor 4, as well as 
the down-regulation of caspase-3 and Grp78 [133]. More recently, the important role of GLP-1 in CVD was confirmed in both preclinical and clinical studies [123].

Glucagon-like peptide-2. GLP-2 is a 33-amino acid peptide, it is an appetite-inhibiting hormone that affects multiple aspects of intestinal physiology, including growth, barrier function, digestion, absorption, motility, and blood flow [134]. GLP-2 induced-pathway involves a unique signaling mechanism and multiple indirect mediators. The GLP-2 receptor is highly homologous to GLP-1 receptor. It is coupled to Gs and Gi/o proteins, and mediates both proliferative and antiapoptotic cellular responses. Recently, Angelone et al. [135] have shown that the heart expresses receptors for GLP-2 in basal conditions. Exogenous GLP-2 induced dose-dependent coronary constriction, as well as inotropic and lusitropic effects. In particular, the cardiovascular effects by GLP-2 were due to Gi/o proteins and involved phospholamban and ERK1/2. The infusion of GLP-2 at concentrations which are in the physiological range induced dose dependent biphasic effects: while at a very low dose $\left(10^{-12} \mathrm{~mol} / \mathrm{L}\right)$ GLP-2 stimulated contractility, a higher concentration $\left(10^{-10} \mathrm{~mol} / \mathrm{L}\right)$ reduced contractility and the rate of relaxation. Contrarily to intestinal cell, the cardiovascular effects induced by GLP-2 were independent from the eNOS/NO system and Akt phosphorylation. The inotropic and lusitropic negative effects induced by GLP-2 were dependent by reduction of phospholamban-(Ser16) phosphorylation [135]. Recently, we reported that GLP-2 infused in the early reperfusion induces a cardioprotective/PostC like effect. GLP-2 PostC limited infarct size and improved post-ischemic recovery of cardiac function. In particular GLP-2 induced an increased phosphorylation of RISK kinases (Akt, ERK1/2 and GSK3 $\beta$ ) and favored the opening of mKATP channels. The co-infusion with a specific inhibitor for PI3k/Akt, wortmannin, abolished the cardioprotective effects and the phosphorylation of all studied kinases [136]. Of note, pre- and post-ischemic treatment with GLP-2 attenuated also intestinal I/R injury, reduced bacterial translocation, inhibited the release of ROS and endothelin-1, and abolished the production of proinflammatory cytokines [137].

\section{Sphingosine-1-phosphate (S1P)}

Sphingolipids and their metabolizing enzymes are beginning to be recognized as critical mediators in biological processes, specifically in autoimmunity, inflammation and cardioprotection. In particular the membrane sphingolipid sphingosine is phosphorylated to S1P by two isoforms of the enzyme sphingosine kinase (SK), SK1 and SK2. These enzymes can be activated by numerous growth factors and cytokines, including IL-1 $\beta$ and TNF- $\alpha$, leading to the generation of S1P. It seems that SK1 is the isoform associated with cell survival. Many actions are mediated through

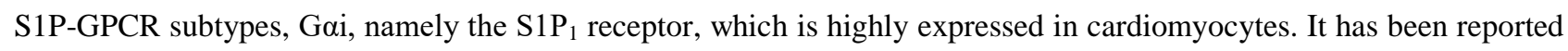
that $\mathrm{S} 1 \mathrm{P}$ is released in both $\mathrm{PreC}$ and PostC and its binding to $\mathrm{S}_{1} \mathrm{P}_{1}$ receptor leads to activation of ERK1/2. $\mathrm{S} 1 \mathrm{P}_{2}$ and $\mathrm{S}_{1} \mathrm{P}_{3}$ receptors are also present on cardiac cells coupled with both Gaq and Gai [138.]. It has been also reported that $\mathrm{S} 1 \mathrm{P}_{3}$ receptor binding leads to the activation of PI3K and Akt. Therefore S1P protection depends on ERK1/2 and in part 
on PI3K/Akt of the RISK pathway in the heart $[59,139]$. Nevertheless, S1P protection is also due to the SAFE pathway. In fact, the protective effects of TNF- $\alpha$ (an element of SAFE pathway) are attenuated by inhibitors of the sphingolipid pathway [140]. Actually, the downstream target of TNF- $\alpha$, TRAF2, induces intracellular formation of S1P via upregulation of SK1 [58]. Moreover, S1P activates STAT3 through the $\mathrm{S}_{1} \mathrm{P}_{2}$ receptor, thus inducing ERK1/2 and then STAT3 activation [59,139]. Recently it has been reported that the levels of phosphorylated STAT3 of SAFE pathway are significantly increased in both the nuclear and mitochondrial fractions in the S1P pre-treated hearts [141]. Therefore, S1P is a trigger for RISK and SAFE pathways and it may be a novel therapeutic target to modulate mitochondrial and nuclear function in CVD in order to protect the heart against I/R.

\section{Opioids}

In addition to pain modulation, opioids are involved in several physiological and pathophysiological regulatory processes, including membrane transports, immune function, feeding, cardiovascular and respiratory control; for reviews, see [142,143]. Three main opioid receptor families, $\mu$-opioid (MOR), $\delta$-opioid (DOR), and $\kappa$-opioid receptor (KOR) have been described, each of which sub-classified into several subtypes. Activation of opioid receptors, in particular DOR, has been demonstrated to preserve cellular vitality following a hypoxic insult, such as I/R, in many systems including the central nervous system [144], the intestine [145], the skeletal muscle [146] and the myocardium [147]. For the purpose of this review, we will focus mainly on the protective effects of opioids against myocardial I/R. Various opioid peptides, including dynorphin-like peptides, enkephalins and $\beta$-endorphin are present within the heart. Cardiac cells themselves are able to synthesize, to store and to release opioid peptides. In particular, elevated levels of these mediators have been found within the heart in stress conditions, such as ischemia.

Gross group was among the first to show cardioprotective effects by opioids [148,149]. Both DOR1 and DOR2 subtypes have been shown to be involved in PreC of the heart. For example, Lasukova et al. [150] showed that a DOR1 agonist exerted antiarrhythmic and cardioprotective effects after I/R. On the other hand, Maslov et al. [151] reported that DOR2 blockers abolished the protective effects of deltorphin II, while a DOR1 antagonist had no effect. The effects of deltorphin II were abrogated by both PKC and NOS, as well as by mKATP channels blockers. Notably, the inhibition of tyrosine kinase, hexamethonium (a ganglion blocker) and catecholamine depletion reversed the antiarrhythmic effect of deltorphin II, but did not alter its positive effect on infarct size. Comparable protective effects have been shown also after KOR activation, being able to mediate both the anti-arrhythmic and infarct sparing effects of ischemic PreC, and to attenuate myocardial apoptosis and necrosis in I/R heart [152].

Other studies have associated cardiac opioid receptors to ischemic PostC protection[84,153]. Kin et al. [84] using the in situ rat heart demonstrated that PostC-induced protection was abrogated in the presence of naloxone, a nonspecific opioid receptor antagonist, suggesting that endogenous opioid binding to its GPCR may also be responsible of the 
infarct-sparing effect of PostC. Moreover, Wang et al. [153] have shown that KOR are involved in PostC-induced cardioprotection, using the same experimental model used by Kin et al. [84].

In conclusion, these data suggest that, together to neuroprotection, DOR-mediated cardioprotection may be a potential useful phenomenon in terms of prevention and treatment of dangerous conditions for life, such as stroke and AMI. Although it is well known that opioid receptor activation during the brief PreC ischemia acts as a trigger for subsequent cardioprotection [149] and that the pharmacological activation of the opioid receptor at the beginning of coronary reperfusion is cardioprotective [154], it remains to be demonstrated whether binding of the endogenous opioid to receptors at time of cardiac reperfusion contributes to conditioning protection.

\section{Platelet-activating factor (PAF)}

Several findings support the hypothesis that PAF may play a dual role in I/R injury of the heart; for reviews, see [155159]. Although the role of PAF in the pathogenesis of myocardial I/R damage is clear, recently it has been demonstrated that very low concentrations of PAF given before an index ischemia exert cardioprotective effects, comparable to those afforded by PreC. PAF belongs to a family of biologically active, structurally related alkyl phosphoglycerides which play an important role in different pathophysiological conditions affecting the cardiovascular system, including cardiac I/R injury. The effects of PAF are due to specific receptors (PAFR), which belong to GPCRs superfamily. Since cardiac cells produce PAF and possess PAFR, it is likely that PAF is an autocrine/paracrine mediator. During cardiac I/R, PAF is released in concentrations $\left(1-1010^{-9} \mathrm{~mol} / \mathrm{L}\right)$ high enough to negatively modulate coronary, contractile and electrical activities. In vivo, PAF may act both directly and through the activation of platelets and pro-inflammatory polymorphonuclear neutrophils, which exacerbate post-ischemic cardiac damage. Actually the deleterious effects exerted by high concentrations of PAF are well established. However several experimental data demonstrated that very low concentrations $\left(10^{-12} \mathrm{~mol} / \mathrm{L}\right)$ of exogenous PAF given before $\mathrm{I} / \mathrm{R}$ induce cardioprotective effects akin to those afforded by ischemic PreC, and that endogenous PAF production contributes in the triggering of ischemic PreC itself [160]. The PreC-like action induced by low concentrations of PAF is due to the activation/phosphorylation of PKC, Akt/PKB and NOS, enzymes included in the RISK pathway. These activation/phosphorylations and the activation of mKATP channels may allow the prompt interventions of signaling pathways leading to the prevention of mPTP at reperfusion [161,162]. In addition, it has been shown that low concentrations of PAF increase the basal intracellular $\mathrm{Ca}^{2+}$ transients in $\mathrm{Ca}^{2+}$-overloaded cardiomyocytes, thus attenuating their time-dependent loss of shortening [52]. These protective effects of PAF depend on NO production and S-nitrosylation of myocardial proteins, rather than the activation of GC and production of cGMP. NO-induced S-nitrosylation of $\mathrm{Ca}^{2+}$ handling proteins, such as $\mathrm{L}^{-t y p e} \mathrm{Ca}{ }^{2+}$ channels, may be responsible for the reduced $\mathrm{Ca}^{2+}$ overload. In conclusion, endogenous synthesis of low levels of PAF during a brief I/R episode may play a pivotal role in the triggering of PreC. It is known that exercise can mimic the 
protective effect of PreC. The fact that low quantities of PAF are released in certain conditions, such as during atrial pacing, exercise, or in non-infarcting ischemia, and the fact that these low quanties of PAF may participate in PreC, suggest the potential importance of a moderate release of PAF, as an attempt by the heart to protect itself against I/R injury. Yet, we should consider that therapies for inflammatory diseases may completely block PAFR, thus inhibiting PAF protective action and this may compromise myocardial postischemic function, since a significant, endogenous cardioprotective pathway is disrupted.

\section{Growth hormone-releasing hormone (GHRH)}

Growth hormone-releasing hormone not only stimulates growth hormone synthesis and release from the pituitary, but also exerts direct effects in extrapituitary tissues, including the cardiovascular system; for reviews, see [163-165]. Indeed, GHRH was shown to exert cardioprotective effects, being able to limit apoptosis induced by serum starvation or isoproterenol in adult rat ventricular myocytes and in the H9c2 cardiac cell line [166]. The protective effects of GHRH are due to its interaction with specific GHRH-R and require activation of ERK1/2 and PI3K/Akt, as well signaling mediated by adenylyl cyclase/cAMP/PKA. In isolated rat hearts subjected to I/R injury, PreC with GHRH strongly reduced the development of infarct size and improved left ventricle (LV) diastolic pressure recovery (i.e. reduced cardiac contracture) following reperfusion. These positive effects were mediated by GHRH-R via a PI3K/Akt signaling, as suggested by their inhibition in the presence of specific antagonists, namely JV-1-36 and LY294002 [166]. Further studies from our laboratory were performed to determine whether GHRH is able to reduce myocardial reperfusion injury also when given at the onset of reperfusion, and to investigate the molecular mechanisms involved in GHRH protective effects [167]. Treatment of isolated I/R rat hearts with GHRH at the onset of reperfusion reduced infarct size at the end of reperfusion and reverted contractile dysfunction. The use of specific pharmacological blockers and Western blot analysis showed that the protective effect of GHRH is due to phosphorylation of either the RISK (PI3K/Akt, ERK1/2 and GSK3ß), or STAT3, as part of the SAFE pathway.

Furthermore, GHRH increased the phosphorylation of eNOS and AMPK, and preserved post-ischemic NAD ${ }^{+}$levels [167]. Taken together, these results suggest that the protective action of GHRH from I/R injury is due to a receptormediated mechanisms, leading to activation of both RISK and SAFE pathways, which converge on mitochondria and possibly on AMPK.

The protective effect of GHRH observed in vitro has been confirmed in vivo by Kanashiro-Takeuchi et al. [168], who demonstrated that JI-38, a potent GHRH agonist (GHRH-A), triggers cardioprotection after AMI. Animals receiving GHRH-A displayed reduced infarct size and improved cardiac structure and function. In addition, GHRH-A increased Bcl-2 antiapoptotic protein in cardiomyocytes and reduced cardiac fibrosis . More recently, Kanashiro-Takeuchi et al. [169] showed that GHRH-A also enhances functional recovery and reverses ventricular remodeling in the setting of 
chronic myocardial infarction. In both studies, circulating levels of GH/insulin-like growth factor (IGF)-I were not increased by GHRH-A, suggesting that GHRH-A exerts direct GH/IGF-I independent effects. In addition, the use of a GHRH antagonist blocked GHRH-A-induced cardioprotection, indicating receptor-mediated mechanisms [169].

\section{Tyrosine kinase receptor activators}

\section{Erythropoietin}

Erythropoietin (Epo) is a 165 amino acids glycoprotein hormone known for its effect on stimulation of proliferation and survival of red blood cells progenitors [170]. Epo is mainly produced in the kidney and liver; however its mRNA, as well as Epo receptor (EpoR) expression, have been shown in many tissues, including the heart, suggesting Epo pleiotropic actions [171].

Epo exerts cardioprotection through antiapoptotic and antihypertrophic effects, as well as mobilization of progenitor cells from the bone marrow [172,173]. Indeed human recombinant (hr)Epo was shown to limit infarct size and LV remodeling in animal models of AMI through antiapoptotic, anti-inflammatory and angiogenic effects [174,175]. The antiapoptotic effects were associated with activation of PI3K/Akt and ERK1/2 pathways. Interestingly, even endogenous Epo-EpoR system plays a protective role in cardiac I/R, at least in part by preventing apoptosis and reducing ROS production [176,177]. The mediator of inflammatory and cytokine response NF-кB was also involved in Epo signaling, thus participating to Epo-mediated cardioprotection. Moreover, EpoR activates STAT3 and p38 MAPK, and increases vascular endothelial growth factor production, therefore increasing angiogenesis [177]. Collectively, these studies, among others, indicate that Epo-induced cardioprotection is likely due to its antiapoptotic, antinflammatory, and proangiogenic effects.

Additional actions of Epo may also contribute to cardioprotection. In fact, Epo was found to enhance cardiomyocyte contractility [178] and to stimulate neuronal and epithelial progenitor cell proliferation [179], suggesting that the hormone may promote the mobilization of non-differentiated stem cells into ischemic area of the myocardium [180]. Epo was also found to act with retinoic acid to support myocardial proliferation in the intact embryonic heart [181] and to promote the proliferation of cultured neonatal myocytes [182].

Based on the encouraging results obtained in animal models, it was suggested that EpoR activation would be a promising target for the treatment of AMI. However, several other studies conducted in both animals and humans provided conflicting results. This was likely because either the dose of hrEpo or the timing of its administration were inappropriate. It was suggested that the dosage of hrEpo, the therapeutic window, the duration of treatment and the experimental model used to replicate AMI in both animal and human studies all had a role in producing conflicting results in heart failure and AMI [171]. 
Importantly, new clinical trials are being performed, also using new EpoR agonists devoid of erythropoietic activity, which still exert cardioprotective actions and should lead to more promising effects, in the attempt to translate the cardioprotection found in experimental models to human patients [183].

\section{Thrombopoietin}

Thrombopoietin (TPO) is a humoral growth factor, which was originally identified for its capacity to induce megakaryocytes differentiation and proliferation. It is produced by the liver and the kidneys, and subsequently cleared from circulation after binding with its receptor c-Mpl, mainly expressed on megakaryocytes and platelets $[184,185]$. Several data point out the role of TPO in different pathophysiological processes involving the heart. For instance, high levels of circulating TPO have been reported in several clinical conditions, such as sepsis and acute coronary syndrome [186]. TPO is able to negatively modulate myocardial contractility, by acting on its receptor c-Mpl on cardiomyocytes and stimulating NO synthesis. Moreover, TPO toghether with IL-1 $\beta$ and TNF- $\alpha$ is responsible of the cardiodepressant effects exerted in vitro by serum of septic shock patients [187]. Interestingly, TPO may also act as a physiological regulator of coronary flow, by acting on receptors present on endothelium and inducing PI3K/Akt dependent eNOS phosphorylation and NO synthesis [188]. In addition, TPO may exert a protective effect on the heart under I/R or oxidative stress.

Indeed, it has been shown that TPO pre-treatment reduced apoptosis and myocardial necrosis, as well as ventricular dysfunction following I/R both in vivo and in vitro in the rat isolated heart. These effects were mediated by Janus kinase (JAK)-2, p42/44 MAPKs, and KATP channels [189].

The anti-ischemic protective effects of TPO have been recently confirmed by Chan et al. [190] on rats subjected to left coronary artery ligation and treated with TPO immediately after induction of AMI and during the 2 following weeks. Four or 8 weeks after the induction of AMI, TPO treatment significantly reduced infarct size and improved left ventricular function and hemodynamic parameters, myocardial morphology and neovascularization. TPO treatment also reversed the alterations in the expression of genes, such as those involved in cytoskeleton organization, vascular and matrix remodeling, muscle development, cell cycling and ion transport, observed in the infarct border zone. Moreover, TPO regulated phosphorylation of STAT3 and ERK, bone morphogenetic protein 1 level, and mobilized EPC colonies in the bone marrow of AMI animals [190].

TPO exerted an antiapoptotic effect in two different in vitro models: the primary neonatal rat cardiomyocytes and the fetal rat cardiomyocyte cell line H9c2. It also protected against cardiac toxicity induced by doxorubicin. In particular, in an in vivo model of doxorubicin-induced acute cardiotoxicity, TPO preserved heart rate, fractional shortening and cardiac output [191]. These previous results have been recently confirmed by studying the effects of TPO in both acuteand chronic-doxorubicin treatment rat models [192]. In both cases, TPO reduced the deleterious effects of doxorubicin 
on cardiac performance and morphologic parameters. TPO also counteracted the altered expressions of some genes, including modulators of ion transport, antiapoptosis, Akt/ERK pathways, signal transduction, cell division, contractile function and protein/matrix remodeling. Also in this case, TPO increased the formation of EPC colonies in the bone marrow. These data suggest that TPO-induced cardioprotection from doxorubicin injury is due to several mechanisms, in particular Akt- and ERK-dependent restoration of regulatory gene activities that are crucial for normal cardiac function.

\section{Insulin}

The studies on insulin mechanisms of action have been classically focused on the metabolic effects of the hormone and its role in the pathophysiology of insulin resistance and diabetes, with major attention on insulin-sensitive targets such as skeletal muscle, adipose tissue, liver, and brain.

The insulin receptor is expressed in a variety of organs, including the heart, indicating pleiotropic actions of insulin. Indeed, insulin signaling has been linked with both cardiovascular physiology and pathological conditions associated with insulin resistance and diabetes, including diabetic cardiomyopathy, coronary artery disease and myocardial ischemia, which ultimately lead to heart failure [193]. A prominent feature of the diabetic myocardium is cardiac hypertrophy, with changes in LV structure and function and by compromised systolic and diastolic function, in the absence of active ischemia. Diabetes-associated hyperglycemia, increased circulating fatty acids and inflammatory cytokines and iperinsulinemia all impair cardiac contractility and cause cardiomyocyte dysfunction and death.

In the heart, insulin induces glucose uptake into cells, by binding to its receptor and mainly through the contractile mediated translocation of the glucose transporters GLUT4 and GLUT1 [194]. Moreover, insulin-induced activation of PI3K/Akt regulates other cellular processes, such as hypertrophy, protein translation, NO generation, apoptosis and autophagy, by activating other intracellular signaling intermediates such as mTOR, S6K, forkhead transcription factors (FOXO) and GSK3 $\beta$. Insulin resistance-induced changes of these signaling pathways may contribute to the developing of cardiac hypertrophy, LV dysfunction and chronic heart failure (CHF) [195]. Insulin also promotes the translocation of the fatty acid transporter CD36 and targets fatty acids to the triglyceride pool. Overall, insulin increases glucose metabolism and reduces fatty acid oxidation. It also regulates mitochondrial oxidative capacity and the adaptation of mitochondria to physiological cardiac hypertrophy [196,197], through mechanisms involving Akt-mTOR-NFkB signaling [198]. Insulin signaling is required for preserving myocardial function and structure in response to pressure overload hypertrophy and ischemia [199-201]. On the other hand, excessive insulin signaling has also been implicated in accelerating LV remodeling in CHF and was found to prevent ischemic PreC [202,203].

Constitutive activation of Akt, a target of different cardioprotective hormones, including insulin [204], was found to preserve cardiac function and to prevent injury after transient cardiac ischemia in vivo [205,206]. Moreover, a recent 
study showed that in a porcine model of acute coronary syndrome, intracoronary insulin, administered at the onset of reperfusion, reduced regional myocardial dysfunction and reduced myocardial apoptosis [207].

In conclusion, the main role of insulin in the heart under physiological conditions is the regulation of substrate utilization. Indeed, insulin promotes cardiomyocyte contraction, increases protein synthesis, stimulates vascular endothelial growth factor and angiogenesis, suppresses apoptosis, promotes cell survival and ameliorates both myocardial microcirculation and coronary artery resistance, leading to increased blood perfusion of myocardium. Conditions such as type 2 diabetes, myocardial ischemia, and cardiac hypertrophy have been shown to alter insulin signaling and insulin actions, further exacerbating the disease states.

\section{Growth factors}

Many growth factors protect the heart from the detrimental effects of $\mathrm{I} / \mathrm{R}$ injury, through the activation of a variety of cell-surface receptors and the recruitment of intracellular signal transduction pathways, including RISK pathway. Here we review a couple of these factors with respect to their ability to confer myocardial protection, whose mechanisms have also been studied in our laboratories. For the other growth factors the reader is kindly redirect to the excellent review of Housenloy and Yellon [208].

\section{Neuregulin}

In the adult heart neuregulin-1 (NRG1) is synthesized by both endocardial and microvascular endothelial cells [209], but its release was recently shown also in coronary artery endothelial cells in culture [210]. Cardiomyocytes express ErbB2 and ErbB4 receptors, and the endothelial derived NRG1 directly binds to ErbB4, inducing a conformational change which leads to the formation of ErbB4 homodimers or ErbB4/ErbB2 heterodimers [211].

The NRG1/ErbB axis is required for cardiac development and in the postnatal adult heart it exerts several pro-survival effects against oxidative stress and cytotoxic agents [212]. The prominence of the protective role of this paracrine pathway in the myocardium is clearly highlighted by the well-known cardiotoxicity of Trastuzumab, an ErbB2 binding antibody used in cancer therapy [213].

Several studies on both neonatal and adult cardiomyocytes reveal that the beneficial effects of NRG1 mainly involve regulation of protein synthesis and sarcomere stability, regulation of cellular metabolism and growth, maintenance and repair of electro-mechanical coupling [214,215]. Moreover, it has also been shown that NRG1 improves diastolic calcium handling by the activation of PI3K, eNOS and PKG [212,216].

Recently, NRG1 has also been proposed as an important cardioprotective agent against myocardial I/R damage. First evidences for this role came from a study by Kuramochi et al. [217], showing that ROS activate NRG-1beta/erbB4 
paracrine signaling, both in vitro (cocultured adult rat cardiomyocytes and cardiac microvascular endothelial cells) and ex vivo (isolated mouse hearts subjected to oxidative stress by I/R injury).

Moreover, NRG1 protection against I/R was also observed in adult murine cardiomyocytes cocultured with human umbilical vein, murine lung microvascular, or human coronary artery EC and confirmed in vivo in mice, where endothelium-selective deletion of NRG1 leads to a significantly decreased tolerance to ischemic insult [210].

NRG1 also revealed significant PreC properties in an in vivo rat model of I/R [218]. This study demonstrated that NRG1 was upregulated after myocardial I/R injury and that NRG1 PreC reduced infarct size and apoptosis, by a PI3K/Akt-dependent mechanism.

The same PI3K/Akt pathway was also involved in NRG1 dependent PostC, as shown in an ex vivo mouse model of I/R injury when NRG1 was infused starting 5 min prior to reperfusion [219]. Interestingly, in these experiments NRG1dependent cardioprotection required eNOS inhibition, suggesting that, during ischemia, superoxide production by uncoupled eNOS annihilates NRG1 PostC. As dysfunctional eNOS occurs in several pathological conditions like diabetes, hypertension and hypercholesterolemia, this study could explain the inefficacy of PostC in models of cardiovascular comorbidities.

The promising animal studies have led to ongoing clinical trials. A phase II, double-blinded, placebo-controlled study has been performed to assess the safety and efficacy of recombinant human NRG-1 in CHF patients. The results showed that recombinant human NRG-1 improved the cardiac function of CHF patients and showed its antiremodeling capability by decreasing end-systolic more than end-diastolic LV volume, thus increasing the LV ejection fraction (LVEF) compared with pre-treatment [220]. These encouraging researches led to further investigate the potential therapeutic application of NRG1 in CHF and to discover useful strategies to increase this endogenous paracrine signal to limit I/R injury.

\section{Ghrelin-associated peptides}

Small peptides GH secretagogues (GHSs) promoting GH-release from the pituitary were initially discovered in 1976 and their receptor (GHS-R) cloned in 1996 [221]. Its endogenous ligand ghrelin is a 28 amino acid peptide initially isolated from the stomach, whose acylation is essential for binding to GHS-R type 1a and its endocrine functions, including stimulation of GH secretion and food intake [221]. Although lacking GHS-R binding, unacylated ghrelin is another ghrelin form, which shares several effects with acylated ghrelin. Ghrelin exerts different activities on cardiovascular system, such as inhibition of cardiac and endothelial cells apoptosis [222], modulation of cardiac contractility through an endothelial cells-NO dependent mechanism [223], and improvement of left ventricular function in I/R heart [224]. Ghrelin attenuated cardiac dysfunction and development of cachexia in rats, as well as in patients with CHF, in which also decreased systemic vascular resistance [225]. In addition, ghrelin was recently found to 
directly modulate cardiac energy substrate metabolism by enhancing free fatty acid oxidation and reducing glucose oxidation in heart failure dogs, thus partially correcting metabolic alterations in heart failure [226].

Obestatin, a recently identified novel ghrelin gene peptide, may also play a significant role in regulating cardiac function in humans, in both physiological and pathological conditions. Actually, higher saliva obestatin levels were found in obese patients with ischemic cardiac disease compared with healthy individuals [227] while decreased levels were present in serum of patients with both obesity and type 2 diabetes mellitus [228]. Moreover, an altered ghrelin to obestatin ratio has been shown in spontaneously hypertensive rats and in CHF patients with cachexia [229,230]. Recently, the serum levels of ghrelin were found to be positively correlated with Angiotensin II in CHF individuals. Interestingly, ghrelin by down-regulating angiotensin 1 receptor inhibited Angiotensin II-induced apoptosis of cardiomyocytes in vitro, thus playing a role in preventing heart failure [231].

The protective effects of obestatin against I/R injury were recently investigated [232]. Pretreatment of isolated rat hearts with obestatin reduced contractile dysfunction and infarct size induced by I/R. Moreover, obestatin exerted an antiapoptotic effect on isolated ventricular myocytes or H9c2 cells subjected to I/R. These cardioprotective effects were due to activation of PI3K, PKC, or ERK1/2 pathways. Specific high-affinity obestatin binding sites were mainly localized on membranes of ventricular cardiomyocytes. Although it has been proposed that obestatin opposes several effects of ghrelin, the protective action of obestatin observed was fully comparable to that induced by ghrelin on the same experimental models [224]. In the myocardium of STZ-treated diabetic rats obestatin exerted a significant beneficial on contractility and ß-adrenergic response via the activation of pro-survival signaling pathways [233].

In conclusion, several evidences indicate that GH secretagogues are emerging as cardioprotective agents. In addition to ghrelin, obestatin, the new described peptide of the ghrelin gene family, demonstrated its ability to play a relevant role in cardiac function and protection. Although future studies are necessary to evidence the mechanisms underpinning the effects of these peptides, the reported findings suggest their potential therapeutic use in cardiac dysfunctions induced by I/R.

\section{Guanylyl cyclase(GC)-linked receptor activators}

\section{Natriuretic peptides}

Atrial (ANP), brain (BNP) and C-type natriuretic peptide (CNP) are polypeptide hormones secreted from the heart as a result of direct wall stress, caused either by stretch or pressure affecting cardiomyocytes, to protect the human body from a volume overload [234]. Also hypoxia was a direct and sufficient stimulus for ANP release from an isolated rodent heart [235] and hypoxia- sensitive elements were found from the promoter sequence of both the ANP and the BNP genes [236,237]. ANP is usually synthesized in the atria, BNP is primarily synthesized in the ventricles and CNP is predominantly produced by the endothelium. Upon their release, natriuretic peptides (NPs) act at multiple sites to 
exert diuretic, natriuretic and vasorelaxant effects. Moreover, ANP, BNP and CNP also act as paracrine factors, inducing antihypertrophic and antifibrotic effects in the heart [238].

NPs exert their hormonal and paracrine effects by binding to three distinct cell surface receptors, the guanylyl cyclaselinked -A and -B receptors (GC-A, GC-B) and the NP-C receptor. The cGMP produced downstream of GC-A/B stimulation can modulate several targets (including PKG and phosphodiesterases 2 and 3). NP-C receptor, which binds all NPs, is not directly linked to a GC enzyme, but is rather coupled to the activation of inhibitory G proteins (Gi) [234,238]. Both cGMP and Gi dependent pathways have been associated to cardioprotection: several studies report that cGMP-induced signaling inhibits hypertrophy, decreases fibrosis, and protects against cardiac I/R [239]. Moreover, upregulation of Gai2 in ischemic myocardium appears to be protective in inducing cell survival pathways preventing myocyte death in response to I/R injury [240].

According to these results, several experimental evidences in different animal models confirm that NPs might protect the heart against infarction when given just prior to reperfusion [241,242]. In particular, it has been shown that administering ANP in rabbit hearts at reperfusion reduced infarction size by activation of PKG, opening of mKATP and stimulation of downstream kinases [75]. Moreover, infusion of CNP prior to or following an ischemic event reduces the size of ventricular infarction by up to $50 \%$, as a result of inhibition of ICa,L, reduction in heart rate and augmented coronary vasodilation [243].

Conversely, other experiments [244] showed that at 30 days postinfarction the survival of ANP-/- mice was markedly better respect to $\mathrm{ANP}^{+/+}$mice, that exhibited increased P-selectin, neutrophil infiltration, infarct size and mortality. As in these experiments mice were subjected to permanent ischemia, the authors suggested that ANP may exert different effects after brief versus prolonged ischemia, two conditions able to activate distinct pathways in the heart [245].

NPs paracrine communication also appears to be involved in cardiac regeneration, as the endothelial GC-A receptor for ANP and BNP is critically involved in cardiac angiogenesis accompanying compensated pressure load-induced hypertrophy [246].

Furthermore, several trials were conducted to determine the beneficial role of ANP/BNP infusion on AMI; however, the results were conflicting. In order to provide a more robust evaluation of the benefits of ANP/BNP in AMI patients, a meta-analysis from 20 trials was recently performed [247]. The results indicated that NPs infusion could improve LVEF\% as compared with control, although it is still premature to conclude that ANP/BNP could be safe respect to renal function deterioration and hypotension.

\section{Agents Acting on Intracellular Pathways}

Gasotransmitters (NO, $\mathrm{H}_{2} \mathrm{~S}$ and $\mathrm{CO}$ ) 
The gasotransmitters NO, hydrogen sulphide $\left(\mathrm{H}_{2} \mathrm{~S}\right)$ and carbon monoxide $(\mathrm{CO})$, modulate many physiological functions [248-250]. In particular, in the cardiovascular system, CO, NO, and $\mathrm{H}_{2} \mathrm{~S}$ induce vasorelaxation, stimulation of angiogenesis, and cardioprotection (Fig. 3) [249,251].

\section{Nitric oxide}

In the myocardium, NO is generated by both enzymatic and non-enzymatic reactions. Three NOS isoforms have been identified, neuronal (nNOS), endothelial (eNOS) and inducible (iNOS) [252]. NOS activity is regulated by cellular compartmentalization, availability of substrates and cofactors, endogenous inhibitors, transcriptional, posttranscriptional, and posttranslational modulations. The production of NO by NOS-independent enzymatic and nonenzymatic reduction of nitrite/nitrate from dietary and endogenous sources is of primary relevance during ischemia, a condition characterized by acidic pH and limited oxygen-dependent NOS activity. The main biological reactions of NO include oxidation to nitrite/nitrate and its reactions with anion superoxide to produce peroxynitrite (ONOO-), a reactive nitrating/nitrosating agent. NO targets metalloenzymes (in particular soluble GC, hemoglobin, and cytochromes), with thiols S-nitrosylation/S-nitrosation, producing S-nitrosothiols (RSNOs) [250,253-255].

NO exerts its cardioprotective role by means of the cGMP/PKG pathway, as a fundamental molecule in the RISK and SAFE cardioprotective signaling pathways, and via S-nitros(yl)ation of proteins such as SERCA and several mitochondrial proteins [38,48-50,250]. During ischemia, there is accumulation of NO generated by both enzymatic and non-enzymatic sources. Then, upon reperfusion, characterized by an abrupt increase of ROS, NO may be converted to peroxynitrite, thus contributing to reperfusion injury. By decreasing peroxynitrite formation, administration of NOS inhibitors at high doses before ischemia may decrease I/R injury. On the other hand, PreC by brief cycles of I/R leads to small increases in NO and peroxynitrite in the trigger phase, leading to a decreased generation of NO and peroxynitrite after infarcting I/R, thus producing cardioprotection [50,253,254]. Indeed, the cardioprotective effect of PreC is lost once NOS is inhibited or in NO deficient conditions such as hyperlipidemia, sensory neuropathy, diabetes,: intact basal myocardial NO generation is needed to achieve cardioprotection by PreC [250,254]. On the other hand, recent experimental studies have shown the usefulness of strategies aimed at increasing cardiac NO metabolites storage before I/R, such as exercise [256,257] or remote preconditioning [258].

Endogenous NO and peroxynitrite are also involved in ischemic PostC. In isolated murine hearts, infarct size was reduced by ischemic PostC, and the eNOS inhibitor L-NG-Nitroarginine Methyl Ester blocked such effect [10,259]. Cardiac peroxynitrite was increased in ischemic PostC in rat hearts. Interestingly, the compound 5,10,15,20-tetrakis(4sulphonatophenyl) porphyrinato iron (FeTPPS, a peroxynitrite decomposition catalyst) inhibited the cardioprotective effect of PostC on infarct size [260]. Similarly, Li et al. [230] showed that when administered before PostC, FeTPPS abrogated its beneficial effect. This suggests that at early reperfusion, NO/ROS interactions contribute to PostC 
cardioprotection. Conversely, ischemic PostC even at late reperfusion reduced infarct size in rodents and humans with a reduction of post-ischemic myocardial iNOS activity and generation of nitrotyrosine [250]. Such effect was mimicked by iNOS inhibition, while 3-morpholinosydnonimine abrogated the effects of PostC [261]. Thus, increased NOperoxynitrite signaling plays a pivotal role in triggering cardioprotection by PostC, which then lowers nitro-oxidative stress in the following full reperfusion, hence contributing to cardioprotection. We have suggested that an initial NOperoxynitrite signaling is followed by an increase in S-nitrosothiols formation in reperfusion phase [38].

Interestingly, infarct size can be reduced independently from PKG by administering MitoSNO during reperfusion [262]. MitoSNO protects murine hearts in vivo against I/R injury by S-nitros(yl)ation of mitochondrial complex I. Indeed, reversible S-nitros(yl)ation of complex I can slow the reactivation of mitochondrial function during reperfusion immediately after ischemia, hence diminishing ROS generation, oxidative damage and tissue necrosis, indicating that rapid complex I reactivation contributes to I/R damage [263]. Beside respiratory complexes, ischemic postconditioning can cause S-nitros(yl)ation of other proteins, which can be blocked by L-NAME, causing a loss of cardioprotection. Moreover, seventy-seven unique proteins with S-nitros(yl)ation sites only modified by PostC have been identified [264].

\section{Hydrogen sulphide}

$\mathrm{H}_{2} \mathrm{~S}$ can be produced endogenously and is present in several cells and tissues in physiological conditions. The main source of $\mathrm{H}_{2} \mathrm{~S}$ in mammals is desulfhydration of cysteine, catalyzed by cystathionine gamma-lyase (CSE), cystathionine beta-synthase (CBS) and 3-mercaptopyruvate sulfurtransferase (3- MST). Different molecular targets, such as different ion channels and signaling proteins mediate the physiological functions of $\mathrm{H}_{2} \mathrm{~S}$. Alterations of $\mathrm{H}_{2} \mathrm{~S}$ metabolism are involved in a variety of pathophysiological conditions such as hypertension, atherosclerosis, CHF, diabetes, cirrhosis, inflammation, sepsis, neurodegenerative disease, erectile dysfunction, and asthma [250,265,266].

Endogenous $\mathrm{H}_{2} \mathrm{~S}$ may modulate cardiovascular function as a potential endogenous gasotransmitter. The effects are mediated by protein S-sulfhydration (a reaction of cysteine residues with $\mathrm{H}_{2} \mathrm{~S}$ ) and activity modification of signaling pathways. The myocardium expresses all three described enzymes that produce $\mathrm{H}_{2} \mathrm{~S}$, but most of the study has focused on of $\mathrm{H}_{2} \mathrm{~S}$ generated by CSE (the most abundant trans-sulfuration pathway enzyme [267]). Nevertheless, the compounds DL-propargylglycine (PAG), or -cyano-L-alanine used for inhibiting $\mathrm{H}_{2} \mathrm{~S}$ synthesis are selective CSE inibitors, allowing other trans-sulfuration pathway enzymes, CBS and 3-MST, to continue $\mathrm{H}_{2} \mathrm{~S}$ production .

PAG inhibition of CSE was able to blunt $\mathrm{H}_{2} \mathrm{~S}$ and increase infarct size in isolated rat hearts [268]. In the same model, exogenous L-cysteine was able to blunt I/R injury through a mechanism dependent on $\mathrm{H}_{2} \mathrm{~S}$ generation [269]. Also, cardiac-specific over expression of cystathionine-lyase modulated the generation of produced $\mathrm{H}_{2} \mathrm{~S}$ and attenuated the 
extent of injury [270]. Also, myocardial I/R injury was exacerbated in mice lacking CSE; conversely, it was blunted by $\mathrm{H}_{2} \mathrm{~S}[271]$

Ischemic PreC necessitates of endogenous $\mathrm{H}_{2} \mathrm{~S}$. In ventricular myocytes, ischemia lowered $\mathrm{H}_{2} \mathrm{~S}$ generation, while this was restored by PreC, showing that endogenous $\mathrm{H}_{2} \mathrm{~S}$ production is crucial in cardioprotection [272]. In rat isolated myocytes, the cardioprotective effects of ischemic PreC on cell viability/morphology was reversed by pharmacological inhibition of CSE inhibition [273]: lowering $\mathrm{H}_{2} \mathrm{~S}$ generation blunted protection from PreC [272].

Ischemic PostC also requires endogenous $\mathrm{H}_{2} \mathrm{~S}$ : $\mathrm{H}_{2} \mathrm{~S}$-producing enzymes are activated in the early phase of reperfusion by ischemic PostC [274], whose cardioprotective effects are blunted by PAG [274]. Furthermore, cardiac-specific over expression of cystathionine gamma-lyase regulated the generation of $\mathrm{H}_{2} \mathrm{~S}$ and reduced myocardial damage [270,275].

The fundamental role played by CSE in the modulation of the I/R injury is further underlined in a recent study from the Lefer Lab [276]. CSE knockout mice showed elevated oxidative stress, dysfunctional eNOS, lower NO levels, and exacerbated myocardial and hepatic I/R injury, while acute $\mathrm{H}_{2} \mathrm{~S}$ therapy restored eNOS function and NO bioavailability, blunting I/R injury. Interestingly, eNOS phosphomutant mice (S1179A) were not protected against I/R by $\mathrm{H}_{2} \mathrm{~S}$ administration, suggesting that $\mathrm{H}_{2} \mathrm{~S}$ protective signaling in the setting of I/R injury is largely dependent on eNOS activation and NO production, further corroborating the evidence on $\mathrm{H}_{2} \mathrm{~S}-\mathrm{NO}$ interaction in the cardiovascular system.

\section{Carbon monoxide}

Endogenous CO is an important, biologically active molecule. Heme oxygenases (HO-1 and HO-2) generate CO as a result of the degradation of heme, with formation also of ferrous iron $\left(\mathrm{Fe}^{2+}\right)$, and biliverdin, which is rapidly reduced to bilirubin, a reaction made possible in the presence of $\mathrm{O}_{2}$ and NADPH. Such a key reaction for iron and bile metabolism leads to the production of bilirubin, which is an important antioxidant. HO-1 and HO-2 are expressed in both atrial and ventricular cardiomyocytes. HO-1 expression is inducible (it is also known as heat shock protein 32), whilst HO-2 expression is constitutive [250], as in many other tissues.

Signaling pathways comprising NO/GC, ROS and MAPKs are regulated by CO. HO is crucial in cellular antioxidant defense and vascular protection, and it may mediate pleiotropic actions of cardiovascular therapeutics [251]. HO-1 is upregulated in the heart after $\mathrm{I} / \mathrm{R}$ and provides cardioprotection, with CO being responsible for most beneficial antiapoptotic and cytoprotective effects [277,278]. Additionally, CO also exerts anti-inflammatory and antihypertensive effects [251].

HO-1 expression and activity were enhanced by hypoxia and gradually declined during reoxygenation with consequent increase of damage. Interestingly, such injury was reduced by incubation with hemin or bilirubin during hypoxia. Also, hemin and bilirubin could attenuate ROS production: hypoxic cardiomyocytes are protected by the HO-1-bilirubin pathway against reoxygenation injury [279]. Additionally, gene delivery of hypoxia-inducible factor-1 alpha (HIF-1 
alpha) induced cardioprotection via the downstream factor HO-1: HL1 cells were protected by HIF-1 alpha and HO-1 against $\mathrm{H}_{2} \mathrm{O}_{2}$-induced damage. The cardioprotective effects exerted by gene delivery of HIF-1 alpha depended on $\mathrm{HO}$ activity suggesting that downstream to HO-1, carbon monoxide as well as bilirubin may be organ effectors [280].

Moreover, HO-1 deficient mice are more susceptible to I/R injury, since they develop right ventricular infarction after prolonged hypoxia, while the myocardium is protected from I/R injury by HO-1 over expression [281,282]. In Dahl salt-sensitive rats fed with high salt diet, coronary arterial HO-1 immunostaining was enhanced, suggesting that coronary HO-1 expression was augumented, promoting increased coronary dilatation in salt-dependent hypertension [277].

The recombinant alpha1C subunit of the human cardiac L-type $\mathrm{Ca}^{2+}$ channel and L-type $\mathrm{Ca}^{2+}$ currents in rat cardiomyocytes can be inhibited by CO [283]. CO was also able to inhibit recombinant and native forms of this channel via ROS of mitochondrial origin $[249,250]$.

Interestingly, $\mathrm{H}_{2} \mathrm{~S}, \mathrm{CO}, \mathrm{GSH}$, and superoxide dismutase levels decreased, and malondialdehyde level increased during myocardial I/R in salt-sensitive rats treated with hydroxylamine and zinc protoporphyrin, a CBS inhibitor and a HO-1 inhibitor, respectively. Whereas HO-1-mRNA and CBS-mRNA levels decreased in comparison to rats subjected to I/R only, thus suggesting that both $\mathrm{CBS} / \mathrm{H}_{2} \mathrm{~S}$ and $\mathrm{HO}-1 / \mathrm{CO}$ systems interact with each other and play a cardioprotective role in $\mathrm{I} / \mathrm{R}[284]$.

On such basis, experimental CO releasing-molecules (CORMs) are being developed, in order to further study the cardioprotective potential of CO [285-288]. These compounds induce cardioprotection in both ex vivo and in vivo experiments, by a series of mechanisms that need to be further elucidated. Nevertheless, they seem to involve Akt [289], the cardiac stromal cell-derived factor-1 $\alpha$ [290 ], inhibition of the mPTP [291], activation of the p38 MAPK $\beta$ and PKC pathways before ischemia. Moreover, they may involve PI3K pathway during reperfusion [292] and activation of the KATP channels [293], Nrf2 and NF-kB, STAT1/3 [294]. Notably only physiologic concentrations of endogenous $\mathrm{CO}$ are cytoprotective, while excessive endogenous levels reflect underlying inflammation, oxidative stress and vascular pathology [264]. Furthermore, high levels of endogenous CO may lead to the production of ROS, [295] impairing NO mediated vasodilation, [296] and promoting adverse vascular remodeling [297]. Indeed, prolonged exposure to CO at high concentrations leads to deleterious effects on myocardial I/R injuries [298] and on cardiac remodeling and ventricular arrhythmias in rats [299,300].

\section{Agents with unknown membrane target}

\section{Chromogranin A- derived peptides: Vasostatin-1 and Catestatin}

Recent data have highlighted the role of two active endogenous peptides derived from Chromogranin A (CgA), Vasostatin-1 (VS-1) and Catestatin (CST), in eliciting important protective effect on the heart undergoing I/R. CgA is a 
$48 \mathrm{kDa}$ acidic glycoprotein of the granins family of proteins, expressed in secretory vesicles of neuroendocrine cells, neurons and other cells including cardiomyocytes, where is co-stored and co-secreted, respectively, with catecholamines and NPs. CgA is cleaved by cell and tissue-specific proteases to numerous peptides, some of them involved in the modulation of different physiological processes, in inflammatory reactions and in the innate immunity. Among these peptides, VS-1 and CST have been extensively studied as regulators of cardiovascular function, mainly because of their ability to counteract the adrenergic signal. Indeed, they are able to control catecholamine release from chromaffin cells and noradrenergic neurons, to exert in vivo and in vitro vasodilatory effects, and to limit the inotropic and lusitropic responses to $\beta$-adrenergic stimulation of the heart. The cardio-suppressive and vasodilator properties of VS-1 and CST have been recently explained as due to a PI3K-dependent-NO release by endothelial cells [301].

Interestingly, the initiating factor for this intracellular cascade has been shown to reside in the interaction with membrane proteoglycans, thus activating a PI3K-dependent caveolae endocytosis, as both peptides are cationic and amphipathic, and exhibit membrane-binding properties resembling those of the cell penetrating peptides [302,303].

Therefore, the established anti-adrenergic and endothelial PI3K/NO signaling of both VS-1 and CST have encouraged to also verify their cardioprotective features. At this regard Cappello et al. [304] showed that in the isolated rat heart exposed to I/R, VS-1 simulated PreC through two different pathways: the first one mediated by A1 receptors activation and the other by NO release. Moreover, VS-1 exerted protective effects on neonatal rat cardiomyocytes, both cultured alone and in the presence of aortic endothelial cells, suggesting the involvement of direct and endothelial dependent mechanisms [305,306].

In isolated rat hearts subjected to global ischemia CST, given for the first 20 min of reperfusion, exerted an infarctsparing effect, reduced contracture and decreased the post-ischemic systolic dysfunction by preventing mPTP opening, with a mechanism involving PI3K/Akt and PKCs [307]. Conversely, in the isolated rat heart exposed to regional ischemia followed by reperfusion, wild type CST and the Pro370Leu variant (allele frequency $~ 0.3 \%$ ) increased myocardial infarct size through Akt dephosphorylation [308]. These diverging results probably reside in the different experimental protocols (global vs regional ischemia) and CST dose applied, resulting in different patterns of tissue response to I/R.

Furthermore, CST was also found to be protective in a model of isolated ventricular myocytes subjected to simulated ischemia, suggesting the presence of a direct effect on cardiomyocytes, independent from the presence of catecholamine or of endothelial cells [307]. CST given in the early reperfusion reduces infarct size and improves cardiac function via a PI3K/Akt, PKC, mitochondrial KATP channels and ROS signaling in the postischemic non-hypertrophic and hypertrophic rat hearts, supporting a potential therapeutic role for CST, even in the presence of comorbidities, such as hypertension and cardiac hypertrophy [301,309]. 


\section{Exosomes and microvesicles}

Exosomes and microvesicles/microparticles are vesicles of 30-100 nm and 100-1000 nm in diameter, respectively, released by several cell types. They are collectively termed extracellular vesicles (EVs) and may represent a powerful tool of inter-cellular communication. In particular, exosomes are capable of transferring proteins, mRNA, and miRNA between cells and they can be proangiogenic and may have cardioprotective properties. In contrast, microvesicles, seem to have more frequently detrimental effects that are pro-thrombotic and pro-inflammatory.

Exosomes are released via an exocytic pathway from multivesicular bodies and have the potential for cell-specific targeting [310]. For instance, a conditioned medium derived from mesenchymal stem cell (MSC) has been shown to mediate cardioprotective effects during I/R protocols via large complexes of 50-100 nm. Therefore MSCs secretes 50to $100-\mathrm{nm}$ particles, which could be observed by electron microscopy. These particles are phospholipid vesicles composed of cholesterol, phosphatidylcholine and sphingomyelin as well as of exosome-associated proteins, e.g., Alix, CD81 and CD9. These particles with a radius of 55-65 nm, purified as a homogeneous population of particles by sizeexclusion fractionation on a HPLC, are likely exosomes. It has been shown that these "purified exosomes" reduced infarct size in a mice model of cardiac I/R injury. Hence, it was concluded that MSC has paracrine cardioprotective effect via exosomes secretion [311]. Recently, it has been reported that exosomes and a few more secreted membrane vesicles, i.e. EVs, act as paracrine signaling mediators within the heart. These vesicles derived from human cardiac progenitors cells [312] increased angiogenesis, decreased cardiomyocyte apoptosis, and improved LVEF. Also mouse cardiac progenitor-derived exosomes protected ischemic heart from acute I/R injury [313]. Exosomes derived from cardiosphere-derived cells have been also proposed as key mediators of cardiosphere-induced cardiac regeneration, [314]. Ischemic PreC markedly increased EV release from the heart. Administration of coronary perfusate from preconditioned hearts attenuated infarct size in non-preconditioned recipient hearts, similarly to cardioprotection afforded by PreC itself on the donor hearts. Perfusates of preconditioned hearts depleted of EVs failed to exert cardioprotection in recipient hearts. This has been the first demonstration that EVs released from the heart after ischemic PreC are necessary for cardioprotection by remote PreC, evidencing the importance of vesicular transfer mechanisms in remote cardioprotection [315]. It has also been suggested that exosomes present in plasma of humans and rats are protective in a Langendorff-perfused rat heart [316]. These studies highlight the importance of exosomes and vesicles in local and distant micro-communication mechanisms after myocardial infarction and their potential utility as cell-free therapeutic candidates. However caution must be used and extensive studies are necessary because the mechanisms of protection are still unknown.

\section{Conclusions: the future of pharmacological conditioning}


There are several endogenous cardioprotective factors (Table 1); we did not consider all of them for space constrain. Our analysis may provide a stimulus and useful heuristic approach for medical oriented research aiming to clarify the risk factors underlying the vulnerability of the human heart and the intrinsic properties of self-protection. Nevertheless, we must admit that there is no consistent evidence for cardioprotection by many endogenous protectant agents when used as pharmacological conditioning drugs in the clinical scenario of AMI, though they have been seen to be protective several times in animal models [46,47,105,317,318]. In addition to the potential confounding effects of comorbidities in man, usually absent in many animal models, the lack of evidence for cardioprotection of pharmacological or ischemic conditioning may relate to the fact that most widely used drugs in clinical scenario, are already cardioprotective, likely using the conditioning/protective RISK and SAFE pathways. Cardioprotective drugs which may "interfere” with conditioning include anxiolytics [319] and antiaggregants [45]. For example, ischemic PreC and PostC have been combined with the P2Y12 inhibitor cangrelor and no additive protection has been found [320]. Also anesthetics are cardioprotective [321,322] and this could be relevant in the surgical suite for cardiovascular and non-cardiovascular interventions with elevated risk of coronary accidents. ACE-I are drugs often used chronically for the treatment of patients with an elevated risk for coronary disease. With chronic use of ACE-I the incidence of AMI is reduced [323,324], and apart from more favorable hemodynamics, their antioxidant properties and pro-bradykinin, pro-nitric oxide effects may contribute to such benefit [240], thus limiting the possibility of additional protection by conditioning protocols [118]. Moreover statins, nitrates, and antidiabetic drugs may treat risk factors thus influencing cardioprotection by modifying cellular signaling involved in protection [231].

If it is true that drugs currently used in clinical practice interfere with conditioning and elicit the same pathways triggered by endogenous factors, future attempts to further decrease both the incidence and the mortality of myocardial infarction should be based on interventions which can prove protective via different mechanisms.

Therefore, future animal studies on cardioprotection should be conducted on top of standard therapy to have a more clinically relevant model. Interventions must demonstrate additive protection in such a model to be considered of clinical value. For instance, it deserves to be investigated whether interventions such as induction of autophagy or remote conditioning [325-327], whose mechanisms are less studied, might display additive effects in the presence of well-known cardioprotective therapies. As said, remote ischemic pre-, per- and post-conditioning can be obtained by repeated cycles of I/R in a limb by inflating/deflating a blood pressure cuff [ 15-18,46,250,315,325,328-333]. Remote conditioning resulted to be a powerful mean to reduce infarct size during programmed interventional and surgical coronary revascularization [328,330,332]. It has also been protective in patients with reperfused AMI [329] and may result protective in the long-term [331-333]. Therefore it may be worthwhile to test remote conditioning as a safe, 
simple, inexpensive and effective cardioprotective approach in the presence of already cardioprotective therapies [334]. In this context the study of exosomes (see above) may open new perspectives.

It has been suggested that other cardioprotective interventions can be associated to enhance protection. For example, mild hypothermia [335,336] and the $\mathrm{Na}^{+}-\mathrm{H}^{+}$exchanger inhibitor cariporide [337] result cardioprotective when applied during ischemia. Thus protection from reperfusion injury via PreC or PostC or substances given in reperfusion could be associated to cooling or cariporide which protect against ischemic damage. Recently it has been reported that the protective effect of the pharmacological PostC agent AMP579 [338] has been added to that of cariporide that protects against an ischemic injury [339]. Yet the addition of cangrelor and cariporide to mild hypothermia nearly abolished the I/R injury in a rat model [320]. Therefore, we must take into account the presence of comorbidities and associated therapies, which should or should not interfere with redox signaling and other cardioprotective pathways, when planning experiments for the validation and identification of cardioprotective drug targets and clinical studies $[46,49,254]$.

By coupling the use of relevant animal models with comorbidities and with concomitant best therapies to further knowledge of endogenous cardioprotective pathways, we hope to identify appropriate candidates for each cardioprotective strategy to be tested in future clinical trials and one day defeat ischemic heart disease. 


\section{List of Abbreviations}

3- MST = 3-mercaptopyruvate sulfurtransferase

AMI = Acute myocardial infarction

AMPK = AMP kinase

ANP $=$ Atrial natriuretic peptide

$\mathrm{AR}=$ Adenosine receptor

$\mathrm{BK}=$ Bradykinin

$\mathrm{BNP}=$ Brain natriuretic peptide

CBS = Cystathionine beta-synthase

CgA = Chromogranin $\mathrm{A}$

cGMP = Cyclic guanosine monophosphate

$\mathrm{CHF}=$ Chronic heart failure

CNP = C-type natriuretic peptide

CsA = Cyclosporine A

CSE $=$ Cystathionine gamma-lyase

CST $=$ Catestatin

CVD = Cardiovascular disease

CX43 = Connexin 43

DOR $=\delta$-opioid receptor

EPCs $=$ Endothelial progenitor cells

Epo $=$ Erythropoietin

EpoR $=$ Epo receptor

ERK $=$ Extracellular signal-regulated kinase

EVs $=$ Extracellular vesicles

GC = Guanylyl cyclase

GHRH $=$ Growth hormone-releasing hormone

GHS $=$ GH secretagogues

GHS-R = GHS receptor

GLP = Glucagon-like peptides

GPCRs $=\mathrm{G}$ protein-coupled receptors

GSK $3 \beta=$ Glycogen synthase kinase 3 beta 
HIF-1 alpha = Hypoxia-inducible factor-1 alpha

$\mathrm{HO}=$ Heme oxygenases

$\mathrm{I} / \mathrm{R}=$ Ischemia/reperfusion

$\mathrm{JAK}=$ Janus kinase

$\mathrm{KOR}=\kappa$-opioid receptor ()

$\mathrm{LV}=$ Left ventricle

LVEF $=$ LV ejection fraction

MAPK = Mitogen-activated protein kinase

MOR $=\mu$-opioid

mPTP $=$ Mitochondrial permeability transition pore

MSCs = Mesenchymal stem cells

NOS = Nitric oxide synthase

NPs $=$ Natriuretic peptides

NRG1 = Neuregulin-1

PAF $=$ Platelet activating factor

PAG = Propargylglycine

PerC $=$ Perconditioning

PI3K = Phosphatidylinositol 3-kinase

$\mathrm{PKB} / \mathrm{Akt}=$ Protein kinase $\mathrm{B}$

PKC = Protein kinase $\mathrm{C}$

PKG = Protein kinase $G$

PostC $=$ Postconditioning

PreC $=$ Preconditioning

RISK = Reperfusion Injury Salvage Kinase

RNS $=$ Reactive nitrogen species

ROS = Reactive oxygen species

S1P = Sphingosine-1-phosphate

SAFE $=$ Survivor Activating Factor Enhancement

SK $=$ Sphingosine kinase

STAT3 $=$ Signal transducer and activator of transcription 3

TNF- $\alpha=$ Tumor necrosis factor-alpha 
TRAF2 $=$ TNF receptor associated factor 2

VS-1 = Vasostatin-1 


\section{FIGURE LEGENDS}

Figure 1. Ischemic conditioning consists of a series of brief periods of ischemia and performed before, during or after the infarcting/index ischemia, which elicit the release of several endogenous cardioprotective agents. These are depicted as circles, triangles and rectangles. Stars represent oxygen and nitrogen reactive species. Cardioprotective agents can be released by several cell types and may act in a paracrine/autocrine fashion to activate membrane receptors and to trigger intracellular pro-survival pathways. Cardioprotective pathways converge on mitochondria where they prevent mitochondrial permeability transition pore (mPTP) formation.

Figure 2. Specific protective actions of cardioprotective agents with metabolic effects.

Figure 3. The gasotransmitters nitric oxide (NO), hydrogen sulphide $\left(\mathrm{H}_{2} \mathrm{~S}\right)$ and carbon monoxide (CO), are produced by the action of enzymes and mediate cardioprotection acting on specific targets. 


\section{Conflict of Interest}

None

\section{Acknowledgements}

The authors are grateful to financial supporters [MIUR 2012-2013 ex60\% (to CP, PP and GA), Compagnia di San Paolo (2011 to RG) ], which allowed the researches reported in the present review.

All authors have contributed substantially to the design, performance, analysis, and writing of the work. 


\section{References}

[1] Murry CE, Jennings RB, Reimer KA. Preconditioning with ischemia: a delay of lethal cell injury in ischemic myocardium. Circulation 1986; 74: 1124-36.

[2] Dawn B, Bolli R. Role of nitric oxide in myocardial preconditioning. Ann N Y Acad Sci 2002; 962: 18-41.

[3] Pagliaro P, Gattullo D, Rastaldo R, Losano G. Ischemic preconditioning: from the first to the second window of protection. Life Sci 2001; 69: 1-15.

[4] Pagliaro P, Moro F, Tullio F, Perrelli MG, Penna C. Cardioprotective pathways during reperfusion: focus on redox signaling and other modalities of cell signaling. Antioxid Redox Signal 2011; 14: 833-50.

[5] Crisafulli A, Melis F, Tocco F, et al. Exercise-induced and nitroglycerin-induced myocardial preconditioning improves hemodynamics in patients with angina. Am J Physiol Heart Circ Physiol 2004; 287: H235-42.

[6] Yellon DM, Downey JM. Preconditioning the myocardium: from cellular physiology to clinical cardiology. Physiol Rev 2003; 83: 1113-51.

[7] Skyschally A, van Caster P, Iliodromitis EK, Schulz R, Kremastinos DT, Heusch G. Ischemic postconditioning: experimental models and protocol algorithms. Basic Res Cardiol 2009; 104: 469-83.

[8] Zhao ZQ, Corvera JS, Halkos ME, et al. Inhibition of myocardial injury by ischemic postconditioning during reperfusion: comparison with ischemic preconditioning. Am J Physiol Heart Circ Physiol 2003; 285: H579-88.

[9] Tsang A, Hausenloy DJ, Mocanu MM, Yellon DM. Postconditioning: a form of "modified reperfusion" protects the myocardium by activating the phosphatidylinositol 3-kinase-Akt pathway. Circ Res 2004; 95: 2302.

[10]Penna C, Cappello S, Mancardi D, et al. Post-conditioning reduces infarct size in the isolated rat heart: role of coronary flow and pressure and the nitric oxide/cGMP pathway. Basic Res Cardiol 2006; 101:168-79.

[11]Penna C, Mancardi D, Rastaldo R, Pagliaro P. Cardioprotection: a radical view Free radicals in pre and postconditioning. Biochim Biophys Acta 2009; 1787: 781-93.

[12]Penna C, Perrelli MG, Pagliaro P. Mitochondrial pathways, permeability transition pore, and redox signaling in cardioprotection: therapeutic implications. Antioxid Redox Signal 2013; 18: 556-99.

[13]Penna C, Mancardi D, Raimondo S, Geuna S, Pagliaro P. The paradigm of postconditioning to protect the heart. J Cell Mol Med 2008; 12: 435-58.

[14]Ludman AJ, Yellon DM, Hausenloy DJ. Cardiac preconditioning for ischaemia: lost in translation. Dis Model Mech 2010; 3: 35-8.

[15]Xin P, Zhu W, Li J, et al. Combined local ischemic postconditioning and remote perconditioning recapitulate cardioprotective effects of local ischemic preconditioning. Am J Physiol Heart Circ Physiol 2010; 298: H181931. Erratum in: Am J Physiol Heart Circ Physiol 2010; 299:H957.

[16]Hausenloy DJ, Yellon DM. The therapeutic potential of ischemic conditioning: an update. Nat Rev Cardiol 2011; 8: 619-29.

[17]Przyklenk K, Whittaker P. Remote ischemic preconditioning: current knowledge, unresolved questions, and future priorities. J Cardiovasc Pharmacol Ther 2011; 16: 255-9.

[18]Tamareille S, Mateus V, Ghaboura N, et al. RISK and SAFE signaling pathway interactions in remote limb ischemic perconditioning in combination with local ischemic postconditioning. Basic Res Cardiol 2011; 106: 1329-39.

[19]Bell RM, Yellon DM. Conditioning the whole heart--not just the cardiomyocyte. J Mol Cell Cardiol 2012; 53: 24-32.

[20]Konstantinidis K, Whelan RS, Kitsis RN. Mechanisms of cell death in heart disease. Arterioscler Thromb Vasc Biol 2012; 32: 1552-62.

[21]Vanlangenakker N, Vanden Berghe T, Krysko DV, Festjens N, Vandenabeele P. Molecular mechanisms and pathophysiology of necrotic cell death. Curr Mol Med 2008; 8: 207-20.

[22]Halestrap AP. Mitochondria and reperfusion injury of the heart -- a holey death but not beyond salvation. J Bioenerg Biomembr 2009; 41: 113-21. 
[23]Cour M, Gomez L, Mewton N, Ovize M, Argaud L. Postconditioning: from the bench to bedside. J Cardiovasc Pharmacol Ther 2011;16: 117-30.

[24]Inserte J, Barrabés JA, Hernando V, Garcia-Dorado D. Orphan targets for reperfusion injury. Cardiovasc Res 2009; 83: 169-78.

[25]Hein TW, Zhang C, Wang W, Chang CI, Thengchaisri N, Kuo L. Ischemia-reperfusion selectively impairs nitric oxide-mediated dilation in coronary arterioles: counteracting role of arginase. FASEB J 2003; 17: 2328 30.

[26]Tsao PS, Ma X, Lefer AM. Activated neutrophils aggravate endothelial dysfunction after reperfusion of the ischemic feline myocardium. Am Heart J 1992; 123: 1464 -71.

[27]Reimer KA, Tanaka M, Murry CE, Richard VJ, Jennings RB. Evaluation of free radical injury in myocardium. Toxicol Pathol 1990;18: 470-80.

[28]Frangogiannis NG, Smith CW, Entman ML. The inflammatory response in myocardial infarction. Cardiovasc Res 2002; 53: 31-47.

[29]Ito H, Maruyama A, Iwakura K, et al. Clinical implications of the 'no reflow' phenomenon. A predictor of complications and left ventricular remodeling in reperfused anterior wall myocardial infarction. Circulation 1996; 93: 223-8.

[30]Morishima I, Sone T, Okumura K, et al. Angiographic no-reflow phenomenon as a predictor of adverse longterm outcome in patients treated with percutaneous transluminal coronary angioplasty for first acute myocardial infarction. J Am Coll Cardiol 2000; 36: 1202-9.

[31]Jaffe R, Dick A, Strauss BH. Prevention and treatment of microvascular obstruction-related myocardial injury and coronary no-reflow following percutaneous coronary intervention: a systematic approach. JACC Cardiovasc Interv 2010; 3: 695-704.

[32] Inserte J, Ruiz-Meana M, Rodríguez-Sinovas A, Barba I, Garcia-Dorado D. Contribution of delayed intracellular pH recovery to ischemic postconditioning protection. Antioxid Redox Signal 2011; 14: 923-39.

[33]Simkhovich BZ, Whittaker P, Przyklenk K, Kloner RA. Transient pre-ischemic acidosis protects the isolated rabbit heart subjected to 30 minutes, but not 60 minutes, of global ischemia. Basic Res Cardiol 1995; 90: 397403.

[34]Asimakis GK, Inners-McBride K, Medellin G, Conti VR. Ischemic preconditioning attenuates acidosis and postischemic dysfunction in isolated rat heart. Am J Physiol 1992; 263: H887-94;

[35] Hausenloy DJ, Wynne AM, Yellon DM. Ischemic preconditioning targets the reperfusion phase. Basic Res Cardiol 2007; 102: 445-52.

[36]Penna C, Rastaldo R, Mancardi D, et al. Post-conditioning induced cardioprotection requires signaling through a redox-sensitive mechanism, mitochondrial ATP-sensitive $\mathrm{K}+$ channel and protein kinase $\mathrm{C}$ activation. Basic Res Cardiol 2006;101: 180-9.

[37]Tullio F, Angotti C, Perrelli MG, Penna C, Pagliaro P. Redox balance and cardioprotection. Basic Res Cardiol 2013; 108: 392.

[38]Penna C, Angotti C, Pagliaro P. Protein S-nitrosylation in preconditioning and postconditioning. Exp Biol Med (Maywood) 2014; 239: 647-62.

[39]Dost T, Cohen MV, Downey JM. Redox signaling triggers protection during the reperfusion rather than the ischemic phase of preconditioning. Basic Res Cardiol 2008;103: 378-84.

[40]Vanden Hoek T, Becker LB, Shao ZH, Li CQ, Schumacker PT. Preconditioning in cardiomyocytes protects by attenuating oxidant stress at reperfusion. Circ Res 2000; 86: 541-8.

[41]Becker LB. New concepts in reactive oxygen species and cardiovascular reperfusion physiology. Cardiovasc Res 2004; 61:461-70.

[42]Liu Y, Yang XM, Iliodromitis EK, et al. Redox signaling at reperfusion is required for protection from ischemic preconditioning but not from a direct PKC activator. Basic Res Cardiol 2008; 103: 54-9.

[43]Hausenloy DJ, Yellon DM. Reperfusion injury salvage kinase signalling: taking a RISK for cardioprotection. Heart Fail Rev 2007; 12: 217-34.

[44]Cohen MV, Downey JM. Ischemic postconditioning: from receptor to end effector. Antioxid Redox Signal 2011; 14: 821-31. 
[45]Cohen MV, Downey JM. Signaling Pathways and Mechanisms of Protection in Pre-and Postconditioning: Historical Perspective and Lessons for the Future. Br J Pharmacol 2014 Sep 10. doi: 10.1111/bph.12903.

[46]Ferdinandy P, Hausenloy DJ, Heusch G, Baxter GF, Schulz R. Interaction of risk factors, comorbidities, and comedications with ischemia/reperfusion injury and cardioprotection by preconditioning, postconditioning, and remote conditioning. Pharmacol Rev 2014; 66:1142-74.

[47]Kleinbongard P, Heusch G. Extracellular signalling molecules in the ischaemic/reperfused heart - druggable and translatable for cardioprotection? Br J Pharmacol 2014 Sep 10. doi: 10.1111/bph.12902.

[48]Heusch G, Boengler K, Schulz R. Cardioprotection: nitric oxide, protein kinases, and mitochondria. Circulation 2008; 118: 1915-19.

[49]Pagliaro P, Penna C. Redox signaling and cardioprotection - translatability and mechanism. Br J Pharmacol 2014; doi: 10.1111/bph.12975.

[50]Murphy E, Kohr M, Sun J, Nguyen T, Steenbergen C. S-nitrosylation: a radical way to protect the heart. J Mol Cell Cardiol 2012; 52: 568-77.

[51]Schulz R, Kelm M, Heusch G. Nitric oxide in myocardial ischemia/reperfusion injury. Cardiovasc Res 2004; 61: 402-13.

[52]Leary PJ, Rajasekaran S, Morrison RR, Tuomanen EI, Chin TK, Hofmann PA. A cardioprotective role for platelet activating factor through NOS dependent S-nitrosylation. Am J Physiol Heart Circ Physiol 2008; 294: H2775-84.

[53]Grube K, Rüdebusch J, Xu Z, et al. Evidence for an intracellular localization of the adenosine A2B receptor in rat cardiomyocytes. Basic Res Cardiol 2011; 106: 385-96.

[54]Garlid KD, Costa AD, Quinlan CL, Pierre SV, Dos Santos P. Cardioprotective signaling to mitochondria. J Mol Cell Cardiol 2009; 46: 858-66.

[55]Heinzel FR, Luo Y, Li X, et al. Impairment of diazoxide-induced formation of reactive oxygen species and loss of cardioprotection in connexin 43 deficient mice. Circ Res 2005; 97: 583-6.

[56]Srisakuldee W, Jeyaraman MM, Nickel BE, Tanguy S, Jiang ZS, Kardami E. Phosphorylation of connexin-43 at serine 262 promotes a cardiac injury-resistant state. Cardiovasc Res 2009; 83: 672-81.

[57]Soetkamp D, Nguyen TT, Menazza S, et al. S-nitrosation of mitochondrial connexin 43 regulates mitochondrial function. Basic Res Cardiol 2014; 109: 433.

[58]Frias MA, Lecour S, James RW, Pedretti S. High density lipoprotein/sphingosine-1-phosphate-induced cardioprotection: role of STAT3 as part of the SAFE pathway. JAKSTAT 2012; 1: 92-100.

[59]Somers SJ, Frias M, Lacerda L, Opie LH, Lecour S. Interplay between SAFE and RISK pathways in sphingosine-1-phosphate-induced cardioprotection. Cardiovasc Drugs Ther 2012; 26: 227-37.

[60]Hausenloy DJ, Lecour S, Yellon DM. Reperfusion injury salvage kinase and survivor activating factor enhancement prosurvival signaling pathways in ischemic postconditioning: two sides of the same coin. Antioxid Redox Signal 2011; 14: 893-907.

[61]Heusch G, Musiolik J, Gedik N, Skyschally A. Mitochondrial STAT3 activation and cardioprotection by ischemic postconditioning in pigs with regional myocardial ischemia/reperfusion. Circ Res 2011; 109: 1302-8.

[62]Boengler K, Hilfiker-Kleiner D, Heusch G, Schulz R. Inhibition of permeability transition pore opening by mitochondrial STAT3 and its role in myocardial ischemia/reperfusion. Basic Res Cardiol 2010; 105: 771-85.

[63]Skyschally A, Schulz R, Heusch G. Cyclosporine A at reperfusion reduces infarct size in pigs. Cardiovasc Drugs Ther 2010; 24: 85-7.

[64]Gedik N, Heusch G, Skyschally A. Infarct size reduction by cyclosporine A at reperfusion involves inhibition of the mitochondrial permeability transition pore but does not improve mitochondrial respiration. Arch Med Sci 2013; 9: 968-75.

[65]De Paulis D, Chiari P, Teixeira G, et al. Cyclosporine A at reperfusion fails to reduce infarct size in the in vivo rat heart. Basic Res Cardiol 2013;108: 379.

[66]Piot C, Croisille P, Staat P, et al. Effect of cyclosporine on reperfusion injury in acute myocardial infarction. $\mathrm{N}$ Engl J Med 2008; 359: 473-81. 
[67]Hausenloy Dj, Kunst G, Boston-Griffiths E, et al. The effect of cyclosporin-A on peri-operative myocardial injury in adult patients undergoing coronary artery bypass graft surgery: a randomised controlled clinical trial. Heart 2014; 100: 544-9.

[68] Shryock JC, Belardinelli L. Adenosine and adenosine receptors in the cardiovascular system: biochemistry, physiology, and pharmacology. Am J Cardiol 1997; 79: 2-10.

[69]Headrick JP, Ashton KJ, Rose'meyer RB, Peart JN. Cardiovascular adenosine receptors: expression, actions and interactions. Pharmacol Ther 2013; 140: 92-111.

[70]Eltzschig HK, Bonney SK, Eckle T. Attenuating myocardial ischemia by targeting A2B adenosine receptors. Trends Mol Med. 2013;19: 345-54.

[71]Köhler D, Eckle T, Faigle M, et al. CD39/ectonucleoside triphosphate diphosphohydrolase 1 provides myocardial protection during cardiac ischemia/reperfusion injury. Circulation 2007; 116: 1784-94.

[72]Peart J, Headrick JP. Adenosinergic cardioprotection: multiple receptors, multiple pathways. Pharmacol Ther 2007;114: 208-21.

[73]Williams-Pritchard G, Knight M, Hoe LS, Headrick JP, Peart JN. Essential role of EGFR in cardioprotection and signaling responses to A1 adenosine receptors and ischemic preconditioning. Am J Physiol Heart Circ Physiol 2011; 300: H2161-68.

[74]Yitzhaki S, Huang C, Liu W, et al. Autophagy is required for preconditioning by the adenosine A1 receptorselective agonist CCPA. Basic Res Cardiol 2009;104:157-67.

[75]Yang XM, Philipp S, Downey JM, Cohen MV. Atrial natriuretic peptide administered just prior to reperfusion limits infarction in rabbit hearts. Basic Res Cardiol 2006; 101: 311-8.

[76]Rork TH, Wallace KL, Kennedy DP, Marshall MA, Lankford AR, Linden J. Adenosine A2A receptor activation reduces infarct size in the isolated, perfused mouse heart by inhibiting resident cardiac mast cell degranulation. Am J Physiol Heart Circ Physiol 2008; 295: H1825-33.

[77]Xi J, McIntosh R, Shen X, et al. Adenosine A2A and A2B receptors work in concert to induce a strong protection against reperfusion injury in rat hearts. J Mol Cell Cardiol 2009; 47: 684-90.

[78]Yang X, Xin W, Yang XM, et al. A2B adenosine receptors inhibit superoxide production from mitochondrial complex I in rabbit cardiomyocytes via a mechanism sensitive to Pertussis toxin. Br J Pharmacol 2011;163: 995-06.

[79]Koeppen M, Harter PN, Bonney S, et al. Adora2b signaling on bone marrow derived cells dampens myocardial ischemia-reperfusion injury. Anesthesiology 2012; 116: 1245-57.

[80]Ge ZD, van der Hoeven D, Maas JE, Wan TC, Auchampach JA. A3 adenosine receptor activation during reperfusion reduces infarct size through actions on bone marrow-derived cells. J Mol Cell Cardiol 2010; 49: 280-86.

[81]de Jonge R, Out M, Maas WJ, de Jong JW. Preconditioning of rat hearts by adenosine A1 or A3 receptor activation. Eur J Pharmacol 2002; 441: 165-72.

[82] Maddock HL, Mocanu MM, Yellon D. Adenosine A3 receptor activation protects the myocardium from reperfusion/reoxygenation injury. Am J Physiol Heart Circ Physiol 2002; 283: H1307-13.

[83]Germack R, Griffin M, Dickenson JM. Activation of protein kinase B by adenosine A1 and A3 receptors in newborn rat cardiomyocytes. J Mol Cell Cardiol 2004; 37: 989-99.

[84]Kin H, Zatta AJ, Lofye MT, et al. Postconditioning reduces infarct size via adenosine receptor activation by endogenous adenosine. Cardiovasc Res 2005; 67: 124-33.

[85]Yang XM, Philipp S, Downey JM, Cohen MV. Postconditioning's protection is not dependent on circulating blood factors or cells but involves adenosine receptors and requires PI3-kinase and guanylyl cyclase activation. Basic Res Cardiol 2005;100: 57-63.

[86]Philipp S, Yang XM, Cui L, Davis AM, Downey JM, Cohen MV. Postconditioning protects rabbit hearts through a protein kinase C-adenosine A2B receptor cascade. Cardiovasc Res 2006; 70: 308-14.

[87]Morrison RR, Tan XL, Ledent C, Mustafa SJ, Hofmann PA. Targeted deletion of A2A adenosine receptors attenuates the protective effects of myocardial postconditioning. Am J Physiol Heart Circ Physiol 2007; 293: H2523-9. 
[88]Methner C, Schmidt K, Cohen MV, Downey JM, Krieg T. Both A2a and A2b adenosine receptors at reperfusion are necessary to reduce infarct size in mouse hearts. Am J Physiol Heart Circ Physiol 2010; 299: H1262-64.

[89]Lasley RD, Kristo G, Keith BJ, Mentzer RM Jr. The A2A/A2B receptor antagonist ZM-241385 blocks the cardioprotective effect of adenosine agonist pretreatment in in vivo rat myocardium. Am J Physiol Heart Circ Physiol 2007; 292: H426-31.

[90]Urmaliya VB, Pouton CW, Ledent C, Short JL, White PJ. Cooperative cardioprotection through adenosine A1 and A2A receptor agonism in ischemia reperfused isolated mouse heart. J Cardiovasc Pharmacol 2010; 56: 379-88.

[91]Zhan E, McIntosh VJ, Lasley RD. Adenosine A A and A B receptors are both required for adenosine A receptor-mediated cardioprotection. Am J Physiol Heart Circ Physiol 2011; 301:H1183-9.

[92] Mahaffey KW, Puma JA, Barbagelata NA, et al. Adenosine as an adjunct to thrombolytic therapy for acute myocardial infarction. Results of a multicenter, randomized, placebo-controlled trial: the Acute Myocardial Infarction Study of Adenosine (AMISTAD) trial. J Am Coll Cardiol 1999; 34: 1711-20.

[93]Ross AM, Gibbons RJ, Stone GW, Kloner RA, Alexander RW, for the AMISTAD-II Investigators. A randomized, double-blinded, placebo-controlled multicenter trial of adenosine as an adjunct to reperfusion in the treatment of acute myocardial infarction (AMISTAD-II). J Am Coll Cardiol 2005; 45: 1775- 80.

[94]Trujillo ME, Scherer PE. Adipose tissue-derived factors: impact on health and disease. Endocrine Reviews 2006; 27: 762-8.

[95]Mattu HS, Randeva HS. Role of adipokines in cardiovascular disease. J Endocrinol 2013; 216: T17-36.

[96]Ding G, Qin Q, He N, et al. Adiponectin and its receptors are expressed in adult ventricular cardiomyocytes and upregulated by activation of peroxisome proliferator-activated receptor gamma. J Mol Cell Cardiol 2007; 43: 73-84.

[97]Amin RH1, Mathews ST, Alli A, Leff T. Endogenously produced adiponectin protects cardiomyocytes from hypertrophy by a PPARgamma-dependent autocrine mechanism. Am J Physiol Heart Circ Physiol 2010; 299:H690-8.

[98]Kadowaki T, Yamauchi T. Adiponectin and adiponectin receptors. Endocr Rev 2005; 26: 439-51.

[99]Cheng KK, Lam KS, Wang Y, et al. Adiponectin-induced endothelial nitric oxide synthase activation and nitric oxide production are mediated by APPL1 in endothelial cells. Diabetes 2007; 56: 1387-94.

[100] Zhu W, Cheng KK, Vanhoutte PM, Lam KS, Xu A. Vascular effects of adiponectin: molecular mechanisms and potential therapeutic intervention. Clin Sci (Lond) 2008; 114:361-74.

[101] Wang Y, Lau WB, Gao E, et al. Cardiomyocyte-derived adiponectin is biologically active in protecting against myocardial ischemia-reperfusion injury. Am J Physiol Endocrinol Metab 2010; 298: E66370.

[102] Tao L, Gao E, Jiao X, et al. Adiponectin cardioprotection after myocardial ischemia/reperfusion involves the reduction of oxidative/nitrative stress. Circulation 2007; 115: 1408-16.

[103] Holland WL, Miller RA, Wang ZV, et al. Receptor-mediated activation of ceramidase activity initiates the pleiotropic actions of adiponectin. Nat Med 2011; 17: 55-63.

[104] Chen Z, Peng IC, Sun W, et al. AMP-activated protein kinase functionally phosphorylates endothelial nitric oxide synthase Ser633. Cir Res 2009; 104: 496-505.

[105] Ouedraogo R, Wu X, Xu SQ, et al. Adiponectin suppression of high-glucose-induced reactive oxygen species in vascular endothelial cells: evidence for involvement of a cAMP signaling pathway. Diabetes 2006; 55: 1840-6.

[106] Kim JE, Song SE, Kim YW, et al. Adiponectin inhibits palmitate-induced apoptosis through suppression of reactive oxygen species in endothelial cells: involvement of cAMP/protein kinase A and AMPactivated protein kinase. J Endocrinol 2010; 207: 35-44.

[107] Fujishima Y, Maeda N, Matsuda K, et al. Effect of adiponectin on cardiac $\beta$-catenin signaling pathway under angiotensin II infusion. Biochem Biophys Res Commun 2014; 444: 224-9.

[108] Simpkin JC, Yellon DM, Davidson SM, Lim SY, Wynne AM, Smith CC. Apelin-13 and apelin-36 exhibit direct cardioprotective activity against ischemia-reperfusion injury. Basic Res Cardiol 2007; 102: 51828. 
[109] Rastaldo R, Cappello S, Folino A, et al. Apelin-13 limits infarct size and improves cardiac postischemic mechanical recovery only if given after ischemia. Am J Physiol Heart Circ Physiol 2011; 300: H2308-15.

[110] Regoli D, Plante GE, Gobeil F Jr. Impact of kinins in the treatment of cardiovascular diseases. Pharmacol Ther 2012; 135: 94-111.

[111] Wall TM, Sheehy R, Hartman JC. Role of bradykinin in myocardial preconditioning. J Pharmacol Exp Ther 1994; 270: 681-9.

[112] Manolis AJ1, Marketou ME, Gavras I, Gavras H. Cardioprotective properties of bradykinin: role of the $\mathrm{B}(2)$ receptor. Hypertens Res 2010; 33: 772-7.

[113] Penna C, Mancardi D, Rastaldo R, Losano G, Pagliaro P. Intermittent activation of bradykinin B2 receptors and mitochondrial KATP channels trigger cardiac postconditioning through redox signaling. Cardiovasc Res 2007;75: 168-77.

[114] Penna C, Mancardi D, Tullio F, Pagliaro P. Postconditioning and intermittent bradykinin induced cardioprotection require cyclooxygenase activation and prostacyclin release during reperfusion. Basic Res Cardiol 2008; 103: 368-77.

[115] Wang X, Wei M, Kuukasjarvi P, et al. The anti-inflammatory effect of bradykinin preconditioning in coronary artery bypass grafting (bradykinin and preconditioning). Scand Cardiovasc J 2009; 43: 72-9.

[116] Pedersen CM, Schmidt MR, Barnes G, et al. Bradykinin does not mediate remote ischaemic preconditioning or ischaemiareperfusion injury in vivo in man. Heart 2011; 97:1857-61.

[117] Jin ZQ, Chen X. Pretreatment with ramiprilat induces cardioprotection against free radical injury in guinea-pig isolated heart: involvement of bradykinin, protein kinase $\mathrm{C}$ and prostaglandins. Clin Exp Pharmacol Physiol 2000; 27: 257-62.

[118] Penna C, Tullio F, Moro F, Folino A, Merlino A, Pagliaro P. Effects of a protocol of ischemic postconditioning and/or captopril in hearts of normotensive and hypertensive rats. Basic Res Cardiol 2010; 105:181-92.

[119] Morris SD, Yellon DM. Angiotensin-converting enzyme inhibitors potentiate preconditioning through bradykinin B2 receptor activation in human heart. J Am Coll Cardiol 1997; 29: 1599-06.

[120] Jaberansari MT, Baxter GF, Muller CA, et al. Angiotensin converting enzyme inhibition enhances a subthreshold stimulus. to elicit delayed preconditioning in pig myocardium. J Am Coll Cardiol 2001; 37: 199601.

[121] Kirkpatrick JN, St John Sutton M. Assessment of ventricular remodeling in heart failure clinical trials. Curr Heart Fail Rep 2012; 9: 328-36.

[122] Ungi I, Palinkas A, Nemes A, et al. Myocardial protection with enalaprilat in patients unresponsive to ischemic preconditioning during percutaneous coronary intervention. Can J Physiol Pharmacol 2008; 86: 82734.

[123] Zhao TC. Glucagon-like peptide-1 (GLP-1) and protective effects in cardiovascular disease: a new therapeutic approach for myocardial protection. Cardiovasc Diabetol 2013;12: 90.

[124] Yamamoto H, Lee CE, Marcus JN, et al. Glucagon-like peptide-1 receptor stimulation increases blood pressure and heart rate and activates autonomic regulatory neurons. J Clin Invest 2002; 110: 43-52.

[125] Zhao T, Parikh P, Bhashyam S, et al. Direct effects of glucagon-like peptide-1 on myocardial contractility and glucose uptake in normal and postischemic isolated rat hearts. J Pharmacol Exp Ther 2006; 317: 1106-13.

[126] Bose AK, Mocanu MM, Carr RD, Yellon DM. Myocardial ischaemia reperfusion injury is attenuated by intact glucagon like peptide-1 (GLP-1) in the in vitro rat heart and may involve the p70s6K pathway. Cardiovasc Drugs Ther 2007, 21: 253-6.

[127] Zhao TC, Taher MM, Valerie KC, Kukreja RC. p38 Triggers late preconditioning elicited by anisomycin in heart: involvement of NF-kappaB and iNOS. Circ Res 2001; 89: 915-22.

[128] Bose AK, Mocanu MM, Carr RD, Brand CL, Yellon DM. Glucagon-like peptide 1 can directly protect the heart against ischemia/reperfusion injury. Diabetes 2005, 54: 146-51. 
[129] Ban K, Noyan-Ashraf MH, Hoefer J, Bolz SS, Drucker DJ, Husain M. Cardioprotective and vasodilatory actions of glucagon-like peptide 1 receptor are mediated through both glucagon-like peptide 1 receptor dependent and independent pathways. Circulation 2008, 117: 2340-50.

[130] Golpon HA, Puechner A, Welte T, Wichert PV, Feddersen CO. Vasorelaxant effect of glucagon-like peptide-(7-36)amide and amylin on the pulmonary circulation of the rat. Regul Pept 2001, 102: 81-6.

[131] Green BD, Hand KV, Dougan JE, McDonnell BM, Cassidy RS, Grieve DJ.GLP-1 and related peptides cause concentration-dependent relaxation of rat aorta through a pathway involving KATP and cAMP. Arch Biochem Biophys 2008, 478: 136-42.

[132] Nyström T, Gonon AT, Sjöholm A, Pernow J. Glucagon-like peptide-1 relaxes rat conduit arteries via an endothelium-independent mechanism. Regul Pept 2005, 125: 173-7.

[133] Liu J, Liu Y, Chen L, Wang Y, Li J. Glucagon-Like peptide-1 analog liraglutide protects against diabetic cardiomyopathy by the inhibition of the endoplasmic reticulum stress pathway. J Diabetes Res 2013; 2013:630537.

[134] Dube PE, Brubaker PL. Frontiers in glucagon-like peptide-2: multiple actions, multiple mediators. Am J Physiol Endocrinol Metab 2007; 293: E460e5

[135] Angelone T, Filice E, Quintieri AM, et al. Receptor identification and physiological characterization of glucagon-like peptide-2 in the rat heart. Nutr Metab Cardiovasc Dis 2012; 22: 486-94.

[136] Penna C, Pasqua T, Perrelli MG, et al. Postconditioning with glucagon like peptide-2 reduces ischemia/reperfusion injury in isolated rat hearts: role of survival kinases and mitochondrial KATP channels. Basic Res Cardiol 2012; 107: 272.

[137] Zhang W, Zhu W, Zhang J, Li N, Li J. Protective effects of glucagon-like peptide 2 on intestinal ischemia-reperfusion rats. Microsurgery 2008; 28: 285-90.

[138] Karliner JS. Sphingosine kinase and sphingosine 1-phosphate in the heart: a decade of progress. Biochim Biophys Acta 2013; 1831: 203-12.

[139] Knapp M. Cardioprotective role of sphingosine-1-phosphate. J Physiol Pharmacol 2011; 62: 601-7.

[140] Lecour S, Smith RM, Woodward B, Opie LH, Rochette L, Sack MN. Identification of a novel role for sphingolipid signaling in $\mathrm{TNF} \alpha$ and ischemic preconditioning mediated cardioprotection. J Mol Cell Cardiol 2002; 34: 509-18.

[141] Kelly-Laubscher RF, King JC, Hacking D, et al. Cardiac preconditioning with sphingosine-1phosphate requires activation of signal transducer and activator of transcription-3. Cardiovasc J Afr 2014; 25: 118-23.

[142] Feng Y, He X, Yang Y, Chao D, Lazarus LH, Xia Y. Current Research on Opioid Receptor Function. Curr Drug Targets 2012; 13: 230-46.

[143] Headrick JP, Pepe S, Peart JN. Non-analgesic effects of opioids: cardiovascular effects of opioids and their receptor systems. Current Pharmaceutical Design 2012; 18: 6090-100.

[144] Borlongan CV, Wang Y, Su TP. Delta opioid peptide (d-ala 2, d-leu 5) enkephalin: linking hiberation and neuroprotection. Front Biosci 2005; 9, 3392-8.

[145] Zhang Y, Wu YX, Hao YB, Dun Y, Yang SP. Role of endogenous opioid peptides in protection of ischemic preconditioning in rat small intestine. Life Sci 2001; 68: 1013-9.

[146] Addison PD, Neligan PC, Ashrafpour H, et al. Noninvasive remote ischemic preconditioning for global protection of skeletal muscle against infarction. Am. J. Physiol. Heart Circ. Physiol 2003; 285, H143543.

[147] Romano MA, Seymour EM, Berry JA, McNish RA, Bolling SF. Relative contribution of endogenous opioids to myocardial ischemic tolerance. J Surg Res 2004; 118: 32-7.

[148] Peart JN, Gross GJ. Exogenous activation of delta- and kappa-opioid receptors affords cardioprotection in isolated murine heart. Basic Res Cardiol 2004; 99: 29-37.

[149] Schultz JE, Rose E, Yao Z, Gross GJ. Evidence for involvement of opioid receptors in ischemic preconditioning in rat hearts. Am J Physiol 1995; 268: H2157-61. 
[150] Lasukova TV, Krylatov AV, Maslov LN, et al. Antiarrhythmic and cardioprotective effect of stimulation of delta1-opiate receptors in myocardial ischemia and reperfusion. Patol Fiziol Eksp Ter 2004; (3): 12-5.

[151] Maslov LN, Lishmanov YB, Oeltgen PR, et al. Activation of peripheral delta2 opioid receptors increases cardiac tolerance to ischemia/reperfusion injury Involvement of protein kinase C, NO-synthase, KATP channels and the autonomic nervous system. Life Sci 2009; 84: 657-63.

[152] Rong F, Peng Z, Ye MX, et al. Myocardial apoptosis and infarction after ischemia/reperfusion are attenuated by kappa-opioid receptor agonist. Arch Med Res 2009; 40: 227-34.

[153] Wang J, Gao Q, Shen J, Ye TM, Xia Q. Kappa-opioid receptor mediates the cardioprotective effect of ischemic postconditioning. Zhejiang Da Xue Xue Bao Yi Xue Ban 2007; 36: 41-7.

[154] Gross ER, Hsu AK, Gross GJ. Opioid-induced cardioprotection occurs via glycogen synthase kinase beta inhibition during reperfusion in intact rat hearts. Circ Res 2004; 94: 960-6.

[155] Montrucchio G, Alloatti G, Camussi G. Role of platelet-activating factor in cardiovascular pathophysiology. Physiol Rev 2000;80: 1669-99.

[156] Prescott SM, Zimmerman GA, Stafforini DM, McIntyre TM. Platelet-activating factor and related lipid mediators. Annu Rev Biochem 2000; 69: 419-45.

[157] Stafforini DM, Mcintyre TM, Zimmerman GA, Prescott SM. Platelet-activating factor, a pleiotrophic mediator of physiological and pathological processes. Crit Rev Clin Lab Sci 2003; 40: 643-72.

[158] Penna C, Bassino E, Alloatti G. Platelet activating factor: the good and the bad in the ischemic/reperfused heart. Exp Biol Med (Maywood) 2011; 236: 390-401.

[159] Detopoulou P, Nomikos T, Fragopoulou E, Chrysohoou C, Antonopoulou S. Platelet Activating Factor in Heart Failure: Potential Role in Disease Progression and Novel Target for Therapy. Curr Heart Fail Rep 2013; 10: 122-9.

[160] Penna C, Alloatti G, Cappello S, et al. Platelet-activating factor induces cardioprotection in isolated rat heart akin to ischemic preconditioning: role of phosphoinositide 3-kinase and protein kinase $\mathrm{C}$ activation. Am J Physiol Heart Circ Physiol 2005; 288: H2512-20.

[161] Penna C, Mognetti B, Tullio F, et al. The platelet activating factor triggers preconditioning-like cardioprotective effect via mitochondrial K-ATP channels and redox-sensible signaling. J Physiol Pharmacol 2008; 59: 47-54.

[162] Penna C, Mognetti B, Tullio F, et al. Post-ischemic activation of kinases in the pre-conditioning-like cardioprotective effect of the platelet-activating factor. Acta Physiol 2009; 197: 175-85.

[163] Barabutis N, Schally AV. Growth hormone-releasing hormone: extrapituitary effects in physiology and pathology. Cell Cycle 2010; 9: 4110-6.

[164] Kiaris H, Chatzistamou I, Papavassiliou AG, Schally AV. Growth hormone-releasing hormone: not only a neurohormone. Trends Endocrinol Metab 2011; 22: 311-7.

[165] Granata R, Isgaard J, Alloatti G, Ghigo E. Cardiovascular actions of the ghrelin gene-derived peptides and growth hormone-releasing hormone. Exp Biol Med (Maywood) 2011; 236: 505-14.

[166] Granata R, Trovato L, Gallo MP, et al. Growth hormone-releasing hormone promotes survival of cardiac myocytes in vitro and protects against ischaemia-reperfusion injury in rat heart. Cardiovasc Res 2009; 83: 303-12.

[167] Penna C, Settanni F, Tullio F, et al. Growth hormone-releasing hormone induces cardioprotection in isolated male rat heart via activation of RISK and SAFE pathways. Endocrinology 2013; 154: 1624-35.

[168] Kanashiro-Takeuchi RM, Tziomalos K, Takeuchi LM, et al. Cardioprotective effects of growth hormone-releasing hormone agonist after myocardial infarction. Proc Natl Acad Sci U S A 2010; 107: $2604-9$.

[169] Kanashiro-Takeuchi RM, Takeuchi LM, Rick FG, et al. Activation of growth hormone releasing hormone (GHRH) receptor stimulates cardiac reverse remodeling after myocardial infarction (MI). Proc Natl Acad Sci U S A 2012; 109: 559-63.

[170] JelkmannW. Erythropoietin: structure, control of production, and function. Physiol Rev 1992; 72: 449-89. 
[171] Sanchis-Gomar F, Garcia-Gimenez JL, Pareja-Galeano H, Romagnoli M, Perez-Quilis C, Lippi G. Erythropoietin and the heart: physiological effects and the therapeutic perspective. Int J Cardiol 2014; 171: 116-25.

[172] Latini R, BrinesM, Fiordaliso F. Do non-hematopoietic effects of erythropoietin play a beneficial role in heart failure? Heart Fail Rev 2008; 13: 415-23.

[173] Wen Y, Zhang XJ, Ma YX, Xu XJ, Hong LF, Lu ZH. Erythropoietin attenuates hypertrophy of neonatal rat cardiac myocytes induced by angiotensin-II in vitro. Scand J Clin Lab Invest 2009; 69: 518-25.

[174] Moon C, Krawczyk M, Ahn D, et al. Erythropoietin reduces myocardial infarction and left ventricular functional decline after coronary artery ligation in rats. Proc Natl Acad Sci U S A 2003; 100: 11612-7.

[175] Prunier F, Pfister O, Hadri L, et al. Delayed erythropoietin therapy reduces post-MI cardiac remodeling only at a dose that mobilizes endothelial progenitor cells. Am J Physiol Heart Circ Physiol 2007; 292: H522-9.

[176] Tada H, Kagaya Y, Takeda M, et al. Endogenous erythropoietin system in nonhematopoietic lineage cells plays a protective role in myocardial ischemia/reperfusion. Cardiovasc Res 2006; 71: 466-77.

[177] Asaumi Y, Kagaya Y, Takeda M, et al. Protective role of endogenous erythropoietin system in nonhematopoietic cells against pressure overload-induced left ventricular dysfunction in mice. Circulation 2007; 115: 2022-32.

[178] Sterin-Borda L, Barcelo AC, Bozzini CE. Erythropoietin improves cardiac contractility in posthypoxic mice. Br J Haematol 2003; 121: 180- 6.

[179] Shingo T, Sorokan ST, Shimazaki T,Weiss S. Erythropoietin regulates the in vitro and in vivo production of neuronal progenitors by mammalian forebrain neural stem cells. J Neurosci 2001; 21: $9733-43$.

[180] Heeschen C, Aicher A, Lehmann R, et al. Erythropoietin is a potent physiologic stimulus for endothelial progenitor cell mobilization. Blood 2003; 102: 1340 - 6 .

[181] Stuckmann I, Evans S, Lasar AB. Erythropoietin and retinoic acid, secreted from the epicardium, are required for cardiac myocyte proliferation. Dev Biol 2003; 255: 334- 49.

[182] Wald MR, Borda ES, Sterin-Borda L. Mitogenic effect of erythropoietin on neonatal rat cardiomyocytes: signal transduction pathways. J Cell Physiol 1996; 167: 461-8.

[183] Mastromarino V, Musumeci MB, Conti E, Tocci G, Volpe M. Erythropoietin in cardiac disease: effective or harmful? J Cardiovasc Med (Hagerstown) 2013; 14: 870-8.

[184] Kaushansky K. Thrombopoietin: a tool for understanding thrombopoiesis. J Thromb Haemost 2003; $1: 1587-92$.

[185] Hitchcock IS, Kaushansky K. Thrombopoietin from beginning to end. Br J Haematol 165: 259-68, 2014.

[186] Stohlawetz P, Folman CC, von dem Borne AE, et al. Effects of endotoxemia on thrombopoiesis in men. Thromb Haemost 1999; 81: 613-7.

[187] Lupia E, Spatola T, Cuccurullo A, et al. Thrombopoietin modulates cardiac contractility in vitro and contributes to myocardial depressing activity of septic shock serum. Basic Res Cardiol 2010; 105: 609-20.

[188] Ramella R, Gallo MP, Spatola T, Lupia E, Alloatti G. A novel role of thrombopoietin as a physiological modulator of coronary flow. Regul Pept 2011; 167: 5-8.

[189] Baker JE, Su J, Hsu A, et al. Human thrombopoietin reduces myocardial infarct size, apoptosis, and stunning following ischaemia/reperfusion in rats. Cardiovasc Res 2008; 77: 44-53.

[190] Chan KY, Zhou L, Xiang P, et al. Thrombopoietin improved ventricular function and regulated remodeling genes in a rat model of myocardial infarction. Int J Cardiol; 2013; 167: 2546-54.

[191] Li K, Sung RY, Huang WZ, et al. Thrombopoietin protects against in vitro and in vivo cardiotoxicity induced by doxorubicin. Circulation 2006; 113; 2211-20.

[192] Chan KY, Xiang P, Zhou L, et al. Thrombopoietin protects against doxorubicin-induced cardiomyopathy, improves cardiac function, and reversely alters specific signalling networks. Eur J Heart Fail 2011; 13: 366-76.

[193] Bugger H, Abel ED. Molecular mechanisms of diabetic cardiomyopathy. Diabetologia 2014; 57: 66071. 
[194] Belke DD, Betuing S, Tuttle MJ, et al. Insulin signaling coordinately regulates cardiac size, metabolism, and contractile protein isoform expression. J Clin Invest 2002; 109: 629-39.

[195] Abel ED, O'Shea KM, Ramasamy R. Insulin resistance: metabolic mechanisms and consequences in the heart. Arterioscler Thromb Vasc Biol 2012; 32: 2068-76.

[196] O’Neill BT, Kim J, Wende AR, et al. A conserved role for phosphatidylinositol 3-kinase but not Akt signaling in mitochondrial adaptations that accompany physiological cardiac hypertrophy. Cell Metab 2007; 6: 294 -306.

[197] Boudina S, Bugger H, Sena S, et al. Contribution of impaired myocardial insulin signaling to mitochondrial dysfunction and oxidative stress in the heart. Circulation 2009; 119: 1272-83.

[198] Parra V, Verdejo HE, Iglewski M, et al. Insulin stimulates mitochondrial fusion and function in cardiomyocytes via the Akt-mTOR-NFкB-Opa-1 signaling pathway. Diabetes 2014; 63: 75-88.

[199] Hu P, Zhang D, Swenson L, Chakrabarti G, Abel ED, Litwin SE. Minimally invasive aortic banding in mice: Effects of altered cardiomyocyte insulin signaling during pressure overload. Am J Physiol Heart Circ Physiol 2003; 285: H1261 -9.

[200] McQueen AP, Zhang D, Hu P, et al. Contractile dysfunction in hypertrophied hearts with deficient insulin receptor signaling: Possible role of reduced capillary density. J Mol Cell Cardiol 2005; 39: 882 - 92.

[201] Sena S, Hu P, Zhang D, et al. Impairedinsulin signaling accelerates cardiac mitochondrial dysfunction after myocardial infarction. J Mol Cell Cardiol 2009; 46: 910 -18.

[202] Shimizu I, Minamino T, Toko H, et al. Excessive cardiac insulin signaling exacerbates systolic dysfunction induced by pressure overload in rodents. J Clin Invest 2010; 120: 1506-14.

[203] Fullmer TM, Pei S, Zhu Y, et al. Insulin suppresses ischemic preconditioning-mediated cardioprotection through Akt-dependent mechanisms. J Mol Cell Cardiol 2013; 64: 20-9.

[204] Baines CP, Wang L, Cohen MV, et al. Myocardial protection by insulin is dependent on phosphatidylinositol 3-kinase but not protein kinase C or KATP channels in the isolated rabbit heart. Basic Res Cardiol 1999;94: 188-98

[205] Matsui T, Tao J, del Monte F, et al. Aactivation preserves cardiac function and prevents injury after transient cardiac ischemia in vivo. Circulation 2001;104: 330-5.

[206] Nagoshi T, Matsui T, Aoyama T, et al. PI3K rescues the detrimental effects of chronic Akt activation in the heart during ischemia/reperfusion injury. J Clin Invest 2005; 115: 2128-38.

[207] Salminen PR, Dahle GO, Moen CA, et al. Intracoronary insulin administered at reperfusion in a porcine model of acute coronary syndrome. Eur Heart J Acute Cardiovasc Care 2014 pii: 2048872614547689. doi: 10.1177/2048872614547689.

[208] Hausenloy DJ, Yellon DM. Cardioprotective growth factors. Cardiovasc Res 2009;83: 179-94.

[209] Lemmens K, Segers VF, Demolder M, De Keulenaer GW. Role of neuregulin-1/ErbB2 signaling in endothelium-cardiomyocyte cross-talk. J Biol Chem 2006; 281: 19469-77.

[210] Hedhli N, Huang Q, Kalinowski A, et al. Endothelium-derived neuregulin protects the heart against ischemic injury. Circulation 2011; 123: 2254-62.

[211] Burgess A, Cho H, Eigenbrot C, et al. An open-and-shut case? Recent insights into the activation of EGF/ErbB receptors. Mol Cell 2003; 12: 541-52.

[212] Gallina C, Brero A, Gallo MP, Levi R. Regulation of intracellular cardiomyocyte calcium stores by peptides: a new approach to cardiac protection. Curr Med Chem 2012; 19: 5782-92.

[213] Guglin M, Cutro R, Mishkin JD. Trastuzumab-induced cardiomyopathy. J Card Fail 2008; 14: 437-44.

[214] Giraud M, Fluck M, Zuppinger C, Suter T. Expressional reprogramming of survival pathways in rat cardiocytes by neuregulin-1beta. J Appl Physiol 2005; 99: 313-22.

[215] Kuramochi Y, Guo X, Sawyer DB. Neuregulin activates erbB2-dependent src/FAK signaling and cytoskeletal remodeling in isolated adult rat cardiac myocytes. J Mol Cell Cardiol 2006; 41: 228-35.

[216] Brero A, Ramella R, Fitou A, et al. Neuregulin-1ß1 rapidly modulates nitric oxide synthesis and calcium handling in rat cardiomyocytes. Cardiovasc Res 2010; 88: 443-52. 
[217] Kuramochi Y, Cote G, Guo X, et al. Cardiac endothelial cells regulate reactive oxygen speciesinduced cardiomyocyte apoptosis through neuregulin-1beta/erbB4 signaling. J Biol Chem 2004; 279: 51141-7.

[218] Fang SJ, Wu XS, Han ZH, et al. Neuregulin-1 preconditioning protects the heart against ischemia/reperfusion injury through a PI3K/Akt-dependent mechanism. Chin Med J (Engl) 2004; 123: 3597604.

[219] Ebner B, Lange SA, Eckert T, et al. Uncoupled eNOS annihilates neuregulin-1 $\beta$-induced cardioprotection: a novel mechanism in pharmacological postconditioning in myocardial infarction. Mol Cell Biochem 2013; 373: 115-23.

[220] Gao R, Zhang J, Cheng L, et al. Phase II, randomized, double-blind, multicenter, based on standard therapy, placebo-controlled study of the efficacy and safety of recombinant human neuregulin-1 in patients with chronic heart failure. J Am Coll Cardiol 2010; 55: 1907-14.

[221] van der Lely AJ, Tschop M, Heiman ML, Ghigo E. Biological, physiological, pathophysiological, and pharmacological aspects of ghrelin. Endocr Rev 2004; 25: 426-57.

[222] Baldanzi G, Filigheddu N, Cutrupi S, et al. Ghrelin and des-acyl ghrelin inhibit cell death in cardiomyocytes and endothelial cells through ERK1/2 and PI 3-kinase/AKT J Cell Biol 2002; 159: 1029-37.

[223] Bedendi I, Alloatti G, Marcantoni A, et al. Cardiac effects of ghrelin and its endogenous derivatives des-octanoyl ghrelin and des-Gln14 ghrelin. Eur J Pharmacol 2003; 476: 87-95.

[224] Chang L, Ren Y, Liu X, et al. Protective effects of ghrelin on ischemia/reperfusion injury in the isolated rat heart. J Cardiovasc Pharmacol 2004; 43:165-70.

[225] Nagaya N, Uematsu M, Kojima M, et al. Elevated circulating level of ghrelin in cachexia associated with chronic heart failure: relationships between ghrelin and anabolic/catabolic factors. Circulation 2001;104: 2034-8.

[226] Mitacchione G, Powers JC, Grifoni G, Woitek F, Lam A, Ly L, Settanni F, Makarewich CA, McCormick R, Trovato L, Houser SR, Granata R, Recchia FA. The gut hormone ghrelin partially reverses energy substrate metabolic alterations in the failing heart. Circ Heart Fail 2014; 7:643-51

[227] Ozbay Y, Aydin S, Dagli AF, et al. Obestatin is present in saliva: alterations in obestatin and ghrelin levels of saliva and serum in ischemic heart disease BMB Rep 2008; 41: 55-61.

[228] Huda MS, Durham BH, Wong SP, et al. Plasma obestatin levels are lower in obese and postgastrectomy subjects, but do not change in response to a meal. Int J Obes (Lond) 2008; 32: 129-35.

[229] Xin X, Ren AJ, Zheng X, et al. Disturbance of circulating ghrelin and obestatin in chronic heart failure patients especially in those with cachexia. Peptides 2009; 30: 2281-5.

[230] Li J, Loukili N, Rosenblatt-Velin N, et al. Peroxynitrite is a key mediator of the cardioprotection afforded by ischemic postconditioning in vivo. PLoS One 2013 8: e70331.

[231] Yang C, Liu Z, Liu K, Yang P. Mechanisms of Ghrelin anti-heart failure: inhibition of Ang II-induced cardiomyocyte apoptosis by down-regulating AT1R expression. PLoS One 2014; 9: e85785.

[232] Alloatti G, Arnoletti E, Bassino E, et al. Obestatin affords cardioprotection to the ischemic-reperfused isolated rat heart and inhibits apoptosis in cultures of similarly stressed cardiomyocytes. Am J Physiol Heart Circ Physiol 2010; 299: H470-81.

[233] Aragno M, Mastrocola R, Ghé C, Arnoletti E, Bassino E, Alloatti G, Muccioli G. Obestatin induced recovery of myocardial dysfunction in type 1 diabetic rats: underlying mechanisms. Cardiovasc Diabetol 2012;11: 129.

[234] Potter LR, Yoder AR, Flora DR, Antos LK, Dickey DM. Natriuretic peptides: their structures, receptors, physiologic functions and therapeutic applications. Handb Exp Pharmacol 2009; 191: 341-66.

[235] Baertschi AJ, Hausmaninger C, Walsh RS, Mentzer RM, Wyatt DA, Pence RA. Hypoxia-induced release of atrial natriuretic factor (ANF) from the isolated rat and rabbit heart. Biochem Biophys Res Commun 1986; 140: 427-33.

[236] Chun YS, Hyun JY, Kwak YG, et al. Hypoxic activation of the atrial natriuretic peptide gene promoter through direct and indirect actions of hypoxia-inducible factor-1. Biochem J 2003; 370: 149-57.

[237] Weidemann A, Klanke B, Wagner M, et al. Hypoxia, via stabilization of the hypoxia-inducible factor HIF-1alpha, is a direct and sufficient stimulus for brain-type natriuretici peptide induction. Biochem J 2008; 409:233-42. 
[238] Del Ry S, Cabiati M, Clerico A. Recent advances on natriuretic peptide system: new promising therapeutic targets for the treatment of heart failure. Pharmacol Res 2013; 76: 190-8.

[239] Lukowski R, Krieg T, Rybalkin SD, Beavo J, Hofmann F. Turning on cGMP-dependent pathways to treat cardiac dysfunctions: boom, bust, and beyond. Trends Pharmacol Sci 2014; 35: 404-13.

[240] DeGeorge BR Jr, Gao E, Boucher M, et al. Targeted inhibition of cardiomyocyte Gi signaling enhances susceptibility to apoptotic cell death in response to ischemic stress. Circulation 2008; 117: $1378-87$.

[241] D’Souza SP, Yellon DM, Martin C, et al. B-type natriuretic peptide limits infarct size in rat isolated hearts via KATP channel opening. Am J Physiol Heart Circ Physiol 2003; 284: H1592-600.

[242] Sangawa K, Nakanishi K, Ishino K, Inoue M, Kawada M, Sano S. Atrial natriuretic peptide protects against ischemia-reperfusion injury in the isolated rat heart. Ann Thorac Surg 2004; 77: 233-7.

[243] Hobbs A, Foster P, Prescott C, Scotland R, Ahluwalia A. Natriuretic peptide receptor-C regulates coronary blood flow and prevents myocardial ischemia/reperfusion injury: novel cardioprotective role for endothelium derived C-type natriuretic peptide. Circulation 2004; 110: 1231-5.

[244] Houng AK, McNamee RA, Kerner A, et al. Atrial natriuretic peptide increases inflammation, infarct size, and mortality after experimental coronary occlusion. Am J Physiol Heart Circ Physiol 2009; 296: H65561.

[245] De Celle T, Vanrobaeys F, Lijnen P, et al. Alterations in mouse cardiac proteome after in vivo myocardial infarction: permanent ischaemia versus ischaemia-reperfusion. Exp Physiol 2005; 90: 593- 606.

[246] Kuhn M, Völker K, Schwarz K, et al. The natriuretic peptide/guanylyl cyclase-a system functions as a stress-responsive regulator of angiogenesis in mice. J Clin Invest 2009; 119: 2019-30.

[247] Lyu T, Zhao Y, Zhang T, et al. Natriuretic peptides as an adjunctive treatment for acute myocardial infarction: insights from the meta-analysis of 1,389 patients from 20 trials. Int Heart J 2014; 55: 8-16.

[248] Caliendo G, Cirino G, Santagada V, Wallace JL. Synthesis and biological effects of hydrogen sulfide (H2S): development of H2S-releasing drugs as pharmaceuticals. J Med Chem 2010; 53: 6275-86.

[249] Szabo C. Gaseotransmitters: New frontiers for translational science. Sci Transl Med 2010; 2: 59ps54.

[250] Andreadou I, Iliodromitis EK, Rassaf T, Schulz R, Papapetropoulos A, Ferdinandy P. The role of gasotransmitters $\mathrm{NO}, \mathrm{H} 2 \mathrm{~S}$ and $\mathrm{CO}$ in myocardial ischaemia/reperfusion injury and cardioprotection by preconditioning, postconditioning and remote conditioning. Br J Pharmacol 2014; doi: 10.1111/bph.12811.

[251] Muchova L, Wong RJ, Hsu M, et al. Statin treatment increases formation of carbon monoxide and bilirubin in mice: a novel mechanism of in vivo antioxidant protection. Can J Physiol Pharmacol 2007 85: 80010.

[252] Zhang Y, Tocchetti CG, Krieg T, Moens AL. Oxidative and nitrosative stress in the maintenance of myocardial function. Free Radic Biol Med 2012; 53: 1531-40.

[253] Ferdinandy P, Schulz R. Nitric oxide, superoxide, and peroxynitrite in myocardial ischaemiareperfusion injury and preconditioning. Br J Pharmacol 2003; 138: 532-43.

[254] Ferdinandy P, Schulz R, Baxter GF. Interaction of cardiovascular risk factors with myocardial ischemia/reperfusion injury, preconditioning, and postconditioning. Pharmacol Rev 2007; 59: 418-58.

[255] Heinrich TA, da Silva RS, Miranda KM, Switzer CH, Wink DA, Fukuto JM. Biological nitric oxide signalling: chemistry and terminology. Br J Pharmacol 2013; 169:1417-29.

[256] Calvert JW, Condit ME, Aragón JP, et al. Exercise protects against myocardial ischemia-reperfusion injury via stimulation of $\beta(3)$-adrenergic receptors and increased nitric oxide signaling: role of nitrite and nitrosothiols. Circ Res 2011;108:1448-58.

[257] Farah C1, Kleindienst A, Bolea G, et al. Exercise-induced cardioprotection: a role for eNOS uncoupling and NO metabolites. Basic Res Cardiol 2013; 108:389.

[258] Rassaf T, Totzeck M, Hendgen-Cotta UB, Shiva S, Heusch G, Kelm M. Circulating nitrite contributes to cardioprotection by remote ischemic preconditioning. Circ Res 2014; 114:1601-10.

[259] Tong G, Aponte AM, Kohr MJ, Steenbergen C, Murphy E, Sun J. Postconditioning leads to an increase in protein S-nitrosylation. Am J Physiol Heart Circ Physiol 2014; 306: H825-32. 
[260] Kupai K, Csonka C, Fekete V, et al. Cholesterol diet-induced hyperlipidemia impairs the cardioprotective effect of postconditioning: role of peroxynitrite. Am J Physiol Heart Circ Physiol 2009; 297: H1729-35.

[261] Fan Q, Yang XC, Liu Y, et al. Postconditioning attenuates myocardial injury by reducing nitrooxidative stress in vivo in rats and in humans. Clin Sci (Lond) 2011; 120: 251-61.

[262] Methner C, Lukowski R, Grube K, et al.. Protection through postconditioning or a mitochondriatargeted S-nitrosothiol is unaffected by cardiomyocyte-selective ablation of protein kinase G. Basic Res Cardiol 2013;108:337.

[263] Chouchani ET, Methner C, Nadtochiy SM, et al. Cardioprotection by S-nitrosation of a cysteine switch on mitochondrial complex I. Nature Med 2013; 19:753-59.

[264] Tong G, Aponte AM, Kohr MJ, Steenbergen C, Murphy E, Sun J. Postconditioning leads to an increase in protein S-nitrosylation. Am J Physiol Heart Circ Physiol 2014;306:H825-32.

[265] Lynn EG, Austin RC. Hydrogen sulfide in the pathogenesis of atherosclerosis and its therapeutic potential. Expert Rev Clin Pharmacol 2011; 4: 97-108.

[266] Wang R. Physiological implications of hydrogen sulfide: a whiff exploration that blossomed. Physiol Rev 2012; 92: 791-896.

[267] Geng B, Yang J, Qi Y, et al. H2S generated by heart in rat and its effects on cardiac function. Biochem Biophys Res Commun 2004; 313: 362-8.

[268] Bliksoen M, Kaljusto ML, Vaage J, Stenslokken KO. Effects of hydrogen sulphide on ischaemiareperfusion injury and ischaemic preconditioning in the isolated, perfused rat heart. Eur J Cardiothorac Surg 2008; 34: 344-9.

[269] Elsey DJ, Fowkes RC, Baxter GF. L-cysteine stimulates hydrogen sulfide synthesis in myocardium associated with attenuation of ischemia-reperfusion injury. J Cardiovasc Pharmacol Ther 2010; 15: 53-9.

[270] Elrod JW, Calvert JW, Morrison J, et al. Hydrogen sulfide attenuates myocardial ischemia-reperfusion injury by preservation of mitochondrial function. Proc Natl Acad Sci USA 2007; 104: 15560-5.

[271] King AL, Polhemus DJ, Bhushan S, et al. Hydrogen sulfide cytoprotective signaling is endothelial nitric oxide synthase-nitric oxide dependent. Proc Natl Acad Sci U S A, 2014; 111: 3182-87.

[272] Bian JS, Yong QC, Pan TT, et al. Role of hydrogen sulfide in the cardioprotection caused by ischemic preconditioning in the rat heart and cardiac myocytes. J Pharmacol Exp Ther 2006; 316: 670-8.

[273] Pan TT, Feng ZN, Lee SW, Moore PK, Bian JS. Endogenous hydrogen sulfide contributes to the cardioprotection by metabolic inhibition preconditioning in the rat ventricular myocytes. J Mol Cell Cardiol 2006; 40: 119-30.

[274] Yong QC, Lee SW, Foo CS, Neo KL, Chen X, Bian J-S. Endogenous hydrogen sulphide mediates the cardioprotection induced by ischemic postconditioning. Am J Physiol Heart Circ Physiol 2008; 295: H1330 H40.

[275] Huang YE, Tang ZH, Xie W, et al. Endogenous hydrogen sulfide mediates the cardioprotection induced by ischemic postconditioning in the early reperfusion phase. Exp Ther Med 2012; 4: 1117-23.

[276] King AL, Polhemus DJ, Bhushan S, et al. Hydrogen sulfide cytoprotective signaling is endothelial nitric oxide synthase-nitric oxide dependent. Proc Natl Acad Sci U S A. 2014;111:3182-7.

[277] Johnson RA, Teran FJ, Durante W, Peyton KJ, Johnson FK. Enhanced heme oxygenase-mediated coronary vasodilation in Dahl salt-sensitive hypertension. Am J Hypertens 2004; 17: 25-30.

[278] Stein AB, Bolli R, Dawn B, et al. Carbon monoxide induces a late preconditioning-mimetic cardioprotective and antiapoptotic milieu in the myocardium. J Mol Cell Cardiol 2012; 52: 228-36.

[279] Foresti R, Goatly H, Green CJ, Motterlini R. Role of heme oxygenase-1 in hypoxia-reoxygenation: requirement of substrate heme to promote cardioprotection. Am J Physiol Heart Circ Physiol 2001; 281: H1976-84.

[280] Czibik G, Sagave J, Martinov V, et al. Cardioprotection by hypoxia-inducible factor 1 alpha transfection in skeletal muscle is dependent on haem oxygenase activity in mice. Cardiovasc Res 2009; 82: 107-14. 
[281] Yet SF, Tian R, Layne MD, et al. Cardiac-specific expression of heme oxygenase-1 protects against ischemia and reperfusion injury in transgenic mice. Circ Res 2001; 89: 168-73.

[282] Yoshida T, Maulik N, Ho YS, Alam J, Das DK. H(mox-1) constitutes an adaptive response to effect antioxidant cardioprotection: A study with transgenic mice heterozygous for targeted disruption of the heme oxygenase-1 gene. Circulation 2001; 103: 1695-701.

[283] Scragg JL, Dallas ML, Wilkinson JA, Varadi G, Peers C. Carbon monoxide inhibits L-type Ca2+ channels via redox modulation of key cysteine residues by mitochondrial reactive oxygen species. J Biol Chem 2008; 283: 24412-19.

[284] Zhu JC, Shao JL, Ma H, Wang JK. Interaction between endogenous cystathionine synthase/hydrogen sulfide and heme oxygenase-1/carbon monoxide systems during myocardial ischemic-reperfusion: experiment with rats. Zhonghua Yi Xue Za Zhi 2008; 88: 3222-55.

[285] Gonzales MA, Mascharak PK. Photoactive metal carbonyl complexes as potential agents for targeted CO delivery. J Inorg Biochem 2014; 133:127-35.

[286] Zobi F. CO and CO-releasing molecules in medicinal chemistry. Future Med Chem 2013; 5:175-188.

[287] Romão CC, Blättler WA, Seixas JD, Bernardes GJ. Developing drug molecules for therapy with carbon monoxide. Chem Soc Rev 2012; 41:3571-83.

[288] Motterlini R, Otterbein LE. The therapeutic potential of carbon monoxide. Nat Rev Drug Discov 2010; 9:728-743

[289] Kondo-Nakamura M, Shintani-Ishida K, Uemura K, Yoshida K. Brief exposure to carbon monoxide preconditions cardiomyogenic cells against apoptosis in ischemia-reperfusion. Biochem Biophys Res Commun 2010; 393:449-54.

[290] Lin HH, Chen YH, Chiang MT, Huang PL, Chau LY. Activator protein-2 $\alpha$ mediates carbon monoxide-induced stromal cell-derived factor- $1 \alpha$ expression and vascularization in ischemic heart. Arterioscler Thromb Vasc Biol 2013; 33:785-794

[291] Queiroga CS, Almeida AS, Martel C, Brenner C, Alves PM, Vieira HL. Glutathionylation of adenine nucleotide translocase induced by carbon monoxide prevents mitochondrial membrane permeabilization and apoptosis. J Biol Chem 2010; 285:17077-88.

[292] Soni HM, Jain MR, Mehta AA. Mechanism(s) involved in carbon monoxide-releasing molecule-2mediated cardioprotection during ischaemia-reperfusion injury in isolated rat heart. Indian J Pharm Sci 2012; 74:281-91.

[293] Soni H, Patel P, Rath AC, Jain M, Mehta AA. Cardioprotective effect with carbon monoxide releasing molecule-2 (CORM-2) in isolated perfused rat heart: Role of coronary endothelium and underlying mechanism. Vascul Pharmacol 2010; 53:68-76.

[294] Stein AB, Guo Y, Tan W, et al. Administration of a CO-releasing molecule induces late preconditioning against myocardial infarction. J Mol Cell Cardiol 2005; 38:127-34.

[295] Zhang J, Piantadosi CA. Mitochondrial oxidative stress after carbon monoxide hypoxia in the rat brain. J Clin Invest 1992; 90:1193-99.

[296] Durante W. Carbon monoxide and bile pigments: surprising mediators of vascular function. Vasc Med 2002; 7:195-202.

[297] Peyton KJ, Reyna SV, Chapman GB, Ensenat D, Liu XM, Wang H, et al. Heme oxygenase-1-derived carbon monoxide is an autocrine inhibitor of vascular smooth muscle cell growth. Blood 2002; 99:4443-4448

[298] Meyer G, André L, Tanguy S, et al. Simulated urban carbon monoxide air pollution exacerbates rat heart ischemia-reperfusion injury. Am J Physiol Heart Circ Physiol 2010; 298:H1445-53.

[299] Andre L, Boissière J, Reboul C, et al. Carbon monoxide pollution promotes cardiac remodeling and ventricular arrhythmia in healthy rats. Am J Respir Crit Care Med 2010; 181:587-95.

[300] Dallas ML, Yang Z, Boyle JP, et al.. Carbon monoxide induces cardiac arrhythmia via induction of the late Na+ current. Am J Respir Crit Care Med 2012; 186:648-56.

[301] Tota B, Angelone T, Cerra MC. The surging role of Chromogranin A in cardiovascular homeostasis. Front Chem 2014; 14; 2:64. 
[302] Ramella R, Boero O, Alloatti G, Angelone T, Levi R, Gallo MP. Vasostatin 1 activates eNOS in endothelial cells through a proteoglycan-dependent mechanism. J Cell Biochem 2010; 110: 70-9.

[303] Fornero S, Bassino E, Ramella R, et al. Obligatory role for endothelial heparan sulphate proteoglycans and caveolae internalization in catestatin-dependent eNOS activation. Biomed Res Int 2014; 2014: 783623.

[304] Cappello S, Angelone T, Tota B, et al. Human recombinant chromogranin A-derived vasostatin-1 mimics preconditioning via an adenosine/nitric oxide signaling mechanism. Am J Physiol Heart Circ Physiol 2007; 293: H719-27.

[305] Yu M, Wang Z, Fang Y, et al. Overexpression of vasostatin-1 protects hypoxia/reoxygenation injuries in cardiomyocytes independent of endothelial cells. Cardiovasc Ther 2012; 30: 145-51.

[306] Liu J, Yang D, Shi S, et al. Overexpression of vasostatin-1 protects hypoxia/reoxygenation injuries in cardiomyocytes-endothelial cells transwell co-culture system. Cell Biol Int 2014; 38: 26-31.

[307] Penna C, Alloatti G, Gallo MP, et al. Catestatin improves post-ischemic left ventricular function and decreases ischemia/reperfusion injury in heart. Cell Mol Neurobiol 2010; 30: 1171-9.

[308] Brar BK, Helgeland E, Mahata SK, et al. Human catestatin peptides differentially regulate infarct size in the ischemic-reperfused rat heart. Regul Pept 2010; 165: 63-70.

[309] Perrelli MG, Tullio F, Angotti et al. Catestatin reduces myocardial ischaemia/reperfusion injury: involvement of PI3K/Akt, PKCs, mitochondrial KATP channels and ROS signalling. Pflugers Arch 2013; 465: 1031-40.

[310] Yellon DM, Davidson SM. Exosomes: nanoparticles involved in cardioprotection? Circ Res 2014; 114: 325-32.

[311] Lai RC, Arslan F, Lee MM, et al. Exosome secreted by MSC reduces myocardial ischemia/reperfusion injury. Stem Cell Res 2010; 4: 214-22.

[312] Barile L, Lionetti V, Cervio E, et al. Extracellular vesicles from human cardiac progenitor cells inhibit cardiomyocyte apoptosis and improve cardiac function after myocardial infarction. Cardiovasc Res 2014; 103: 530-41.

[313] Chen L, Wang Y, Pan Y, et al. Cardiac progenitor-derived exosomes protect ischemic myocardium from acute ischemia/reperfusion injury. Biochem Biophys Res Commun 2013; 431: 566-71.

[314] Ibrahim AG, Cheng K, Marbán E. Exosomes as critical agents of cardiac regeneration triggered by cell therapy. Stem Cell Reports 2014; 2: 606-19.

[315] Giricz Z, Varga ZV, Baranyai T, et al. Cardioprotection by remote ischemic preconditioning of the rat heart is mediated by extracellular vesicles. J Mol Cell Cardiol 2014; 68: 75-8.

[316] Bell R, Beeuwkes R, Bøtker HE, et al. Trials, tribulations and speculation! Report from the 7th Biennial Hatter Cardiovascular Institute Workshop. Basic Res Cardiol 2012;107:300.

[317] Garcia-Dorado D, Otaegui I, Rodriguez Palmoares JF, et al. Primary results of the PROMISE trial: myocardial protection with intracoronary adenosine given before reperfusion in patients with STEMI. Europ Heart J 2013; 34 (suppl 1): 669-70.

[318] Wong GT, Huang Z, Ji S, Irwin MG. Remifentanil reduces the release of biochemical markers of myocardial damage after coronary artery bypass surgery: a randomized trial. J Cardiothorac Vasc Anesth 2010; 24: 790-6.

[319] Obame FN, Zini R, Souktani R, Berdeaux A, Morin D. Peripheral benzodiazepine receptor-induced myocardial protection is mediated by inhibition of mitochondrial membrane permeabilization. J Pharmacol Exp Ther 2007; 323: 336-45.

[320] Yang XM, Cui L, Alhammouri A, Downey JM, Cohen MV. Triple therapy greatly increases myocardial salvage during ischemia/reperfusion in the in situ rat heart. Cardiovasc Drugs Ther 2013; 27: 40312.

[321] Kato R, Foex P. Myocardial protection by anesthetic agents against ischemia-reperfusion injury: an update for anesthesiologists. Can J Anaesth 2002; 49: 777-91.

[322] Zaugg M, Lucchinetti E, Behmanesh S, Clanachan AS. Anesthetic cardioprotection in clinical practice from proof-of-concept to clinical applications. Curr Pharm Des 2014; doi: $10.2174 / 1381612820666140204120829$. 
[323] McAlister FA. Angiotensin-converting enzyme inhibitors or angiotensin receptor blockers are beneficial in normotensive atherosclerotic patients: a collaborative meta-analysis of randomized trials. Eur Heart J 2012; 33: 505-14.

[324] Savarese G, Costanzo P, Cleland JG, et al. A meta-analysis reporting effects of angiotensinconverting enzyme inhibitors and angiotensin receptor blockers in patients without heart failure. J Am Coll Cardiol 2013; 61: 131-42.

[325] Lim SY, Hausenloy DJ. Remote ischemic conditioning: from bench to bedside. Front Physiol 2012; 3: 27.

[326] Sala-Mercado JA, Wider J, Undyala VVR, et al. Profound cardioprotection with chloramphenicol succinate in the swine model of myocardial ischemia-reperfusion injury. Circulation 2010; 122: S179-84.

[327] Shiomi M, Miyamae M, Takemura G, et al. Induction of autophagy restores the loss of sevoflurane cardiac preconditioning seen with prolonged ischemic insult. Eur J Pharmacol 2014 Feb 5;724:58-66. doi: 10.1016/j.ejphar.2013.12.027

[328] Hausenloy DJ, Mwamure PK, Venugopal V, et al. Effect of remote ischaemic preconditioning on myocardial injury in patients undergoing coronary artery bypass graft surgery: a randomized controlled trial. Lancet 2007; 370: 575-9.

[329] Botker HE, Kharbanda R, Schmidt MR, et al. Remote ischaemic conditioning before hospital admission, as a complement to angioplasty, and effect on myocardial salvage in patients with acute myocardial infarction: a randomised trial. Lancet 2010; 375: 727-34.

[330] Thielmann M, Kottenberg E, Boengler K, et al. Remote ischemic preconditioning reduces myocardial injury after coronary artery bypass surgery with crystalloid cardioplegic arrest. Basic Res Cardiol 2010; 105: 657-64.

[331] Davies WR, Brown AJ, Watson W, et al. Remote ischemic preconditioning improves outcome at 6 years after elective percutaneous coronary intervention: The CRISP Stent Trial Long-Term Follow-Up. Circ Cardiovasc Interv 2013; 6: 246-51.

[332] Thielmann M, Kottenberg E, Kleinbongard P, et al. Cardioprotective and prognostic effects of remote ischaemic preconditioning in patients undergoing coronary artery bypass surgery: a single-centre randomised, double-blind, controlled trial. Lancet 2013; 382: 597-604.

[333] Sloth AD, Schmidt MR, Munk K, et al. Improved long-term clinical outcomes in patients with STelevation myocardial infarction undergoing remote ischaemic conditioning as an adjunct to primary percutaneous coronary intervention. Eur Heart J 2014; 35: 168-75.

[334] Heusch G. Remote conditioning: the future of cardioprotection? J Cardiovasc Med (Hagerstown ) 2013; 14: 176-9.

[335] Tissier R, Hamanaka K, Kuno A, Parker JC, Cohen MV, Downey JM. Total liquid ventilation provides ultra-fast cardioprotective cooling. J Am Coll Cardiol 2007; 49: 601-5.

[336] Miki T, Liu GS, Cohen MV, Downey JM. Mild hypothermia reduces infarct size in the beating rabbit heart: a practical intervention for acute myocardial infarction? Basic Res Cardiol 1998; 93: 372-83.

[337] Miura T, Ogawa T, Suzuki K, Goto M, Shimamoto K. Infarct size limitation by a new Na+-H+ exchange inhibitor, Hoe 642: difference from preconditioning in the role of protein kinase C. J Am Coll Cardiol 1997; 29: 693-701.

[338] Xu Z, Downey JM, Cohen MV. Timing and duration of administration are crucial for antiinfarct effect of AMP 579 infused at reperfusion in rabbit heart. Heart Dis 2003; 5: 368-71.

[339] Xu Z, Jiao Z, Cohen MV, Downey JM. Protection from AMP 579 can be added to that from either cariporide or ischemic preconditioning in ischemic rabbit heart. J Cardiovasc Pharmacol 2002; 40: 510-8. 
Paraerine/Autoerine Action of Cardioprotective Agents

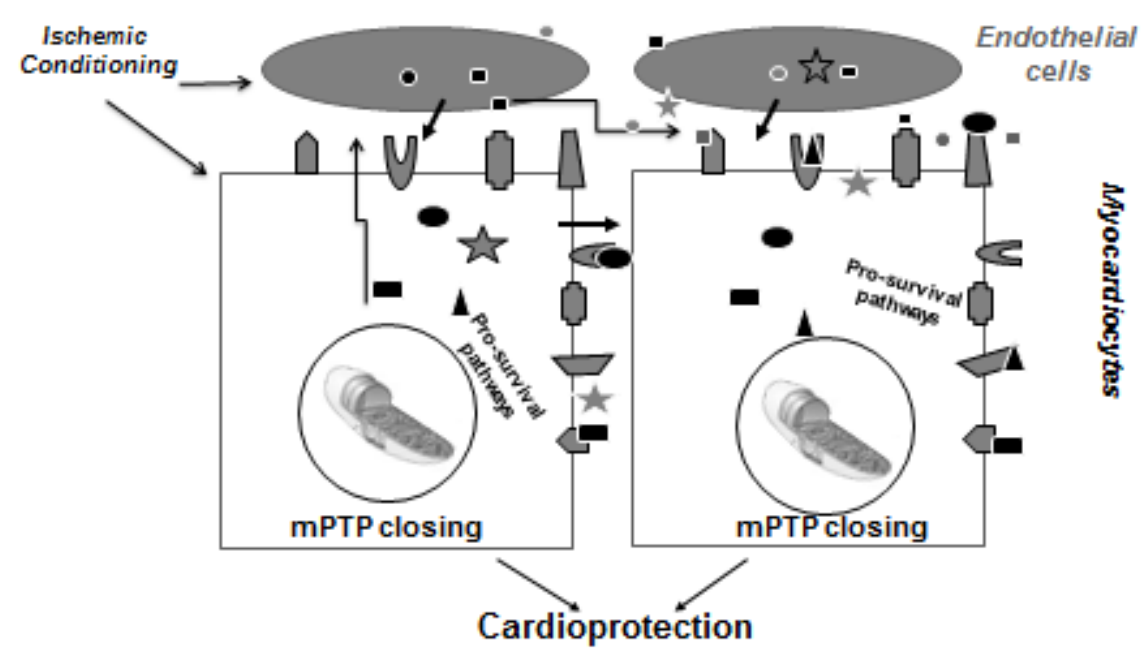

Fig. 1 


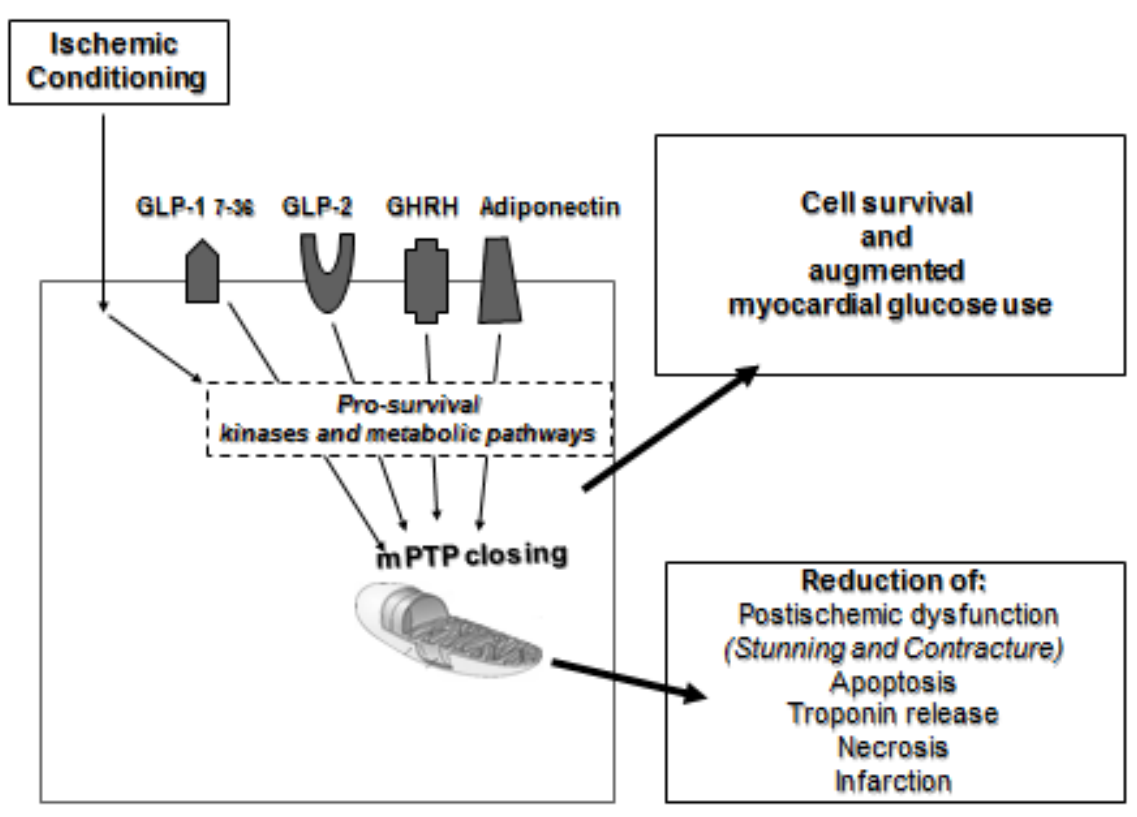

Fig. 2 


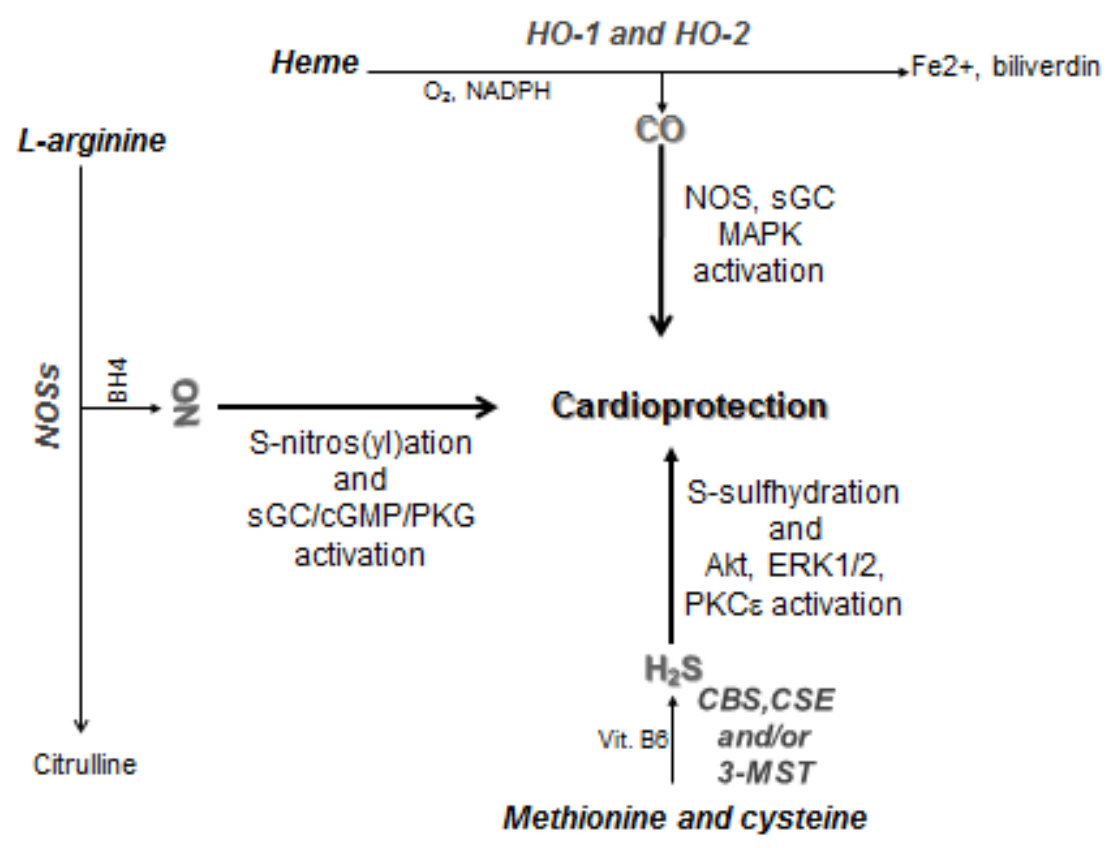

Fig. 3 
Table 1. Endogenous cardioprotective factors

\begin{tabular}{|l|c|c|c|l|}
\hline \multicolumn{1}{|c|}{ Substance } & $\begin{array}{c}\text { Time of } \\
\text { Administration }\end{array}$ & $\begin{array}{c}\text { I/R } \\
\text { Injury }\end{array}$ & $\begin{array}{c}\text { Clinical } \\
\text { trials }\end{array}$ & Ref \\
\hline Adenosine & Pre and Post & $\downarrow$ & Yes & $80-87,92,93$ \\
\hline Adipocytokines & Pre and Post & $\downarrow$ & None & $101,102,108,109$ \\
\hline Bradykinin & Pre and Post & $\downarrow$ & Yes & $111-114,121,122$ \\
\hline $\begin{array}{l}\text { Glucagon-like } \\
\text { peptide }\end{array}$ & Pre and Post & $\downarrow$ & Yes & $123,125,126,136$ \\
\hline Opiods & Pre and Post & $\downarrow$ & None & $84,150-153$ \\
\hline PAF & Pre & $\downarrow$ & None & 52,160-162 \\
\hline GHRH & Pre and Post & $\downarrow$ & None & $166-168$ \\
\hline EPO & Pre & $\downarrow$ & Yes & $171,174-177$ \\
\hline TPO & Pre and Post & $\downarrow$ & None & 189,190 \\
\hline Insulin & Pre & $\downarrow$ & None & $199-201$ \\
\hline NRG & Pre and Post & $\downarrow$ & Yes & $210,218-220$ \\
\hline $\begin{array}{l}\text { Ghrelin-associated } \\
\text { peptides }\end{array}$ & Pre and Post & $\downarrow$ & None & $224,232,233$ \\
\hline Natriuretic peptides & Pre and Post & $\downarrow$ & Yes & $75,240-243,247$ \\
\hline Gasotransmitters & Pre and Post & $\downarrow$ & Yes & $\begin{array}{l}9,250,253-255,259,260,268- \\
274,277,278,281,282\end{array}$ \\
\hline $\begin{array}{l}\text { Chromogranin A- } \\
\text { derived peptides }\end{array}$ & Pre and Post & $\downarrow$ & None & $304,307,309$ \\
\hline
\end{tabular}




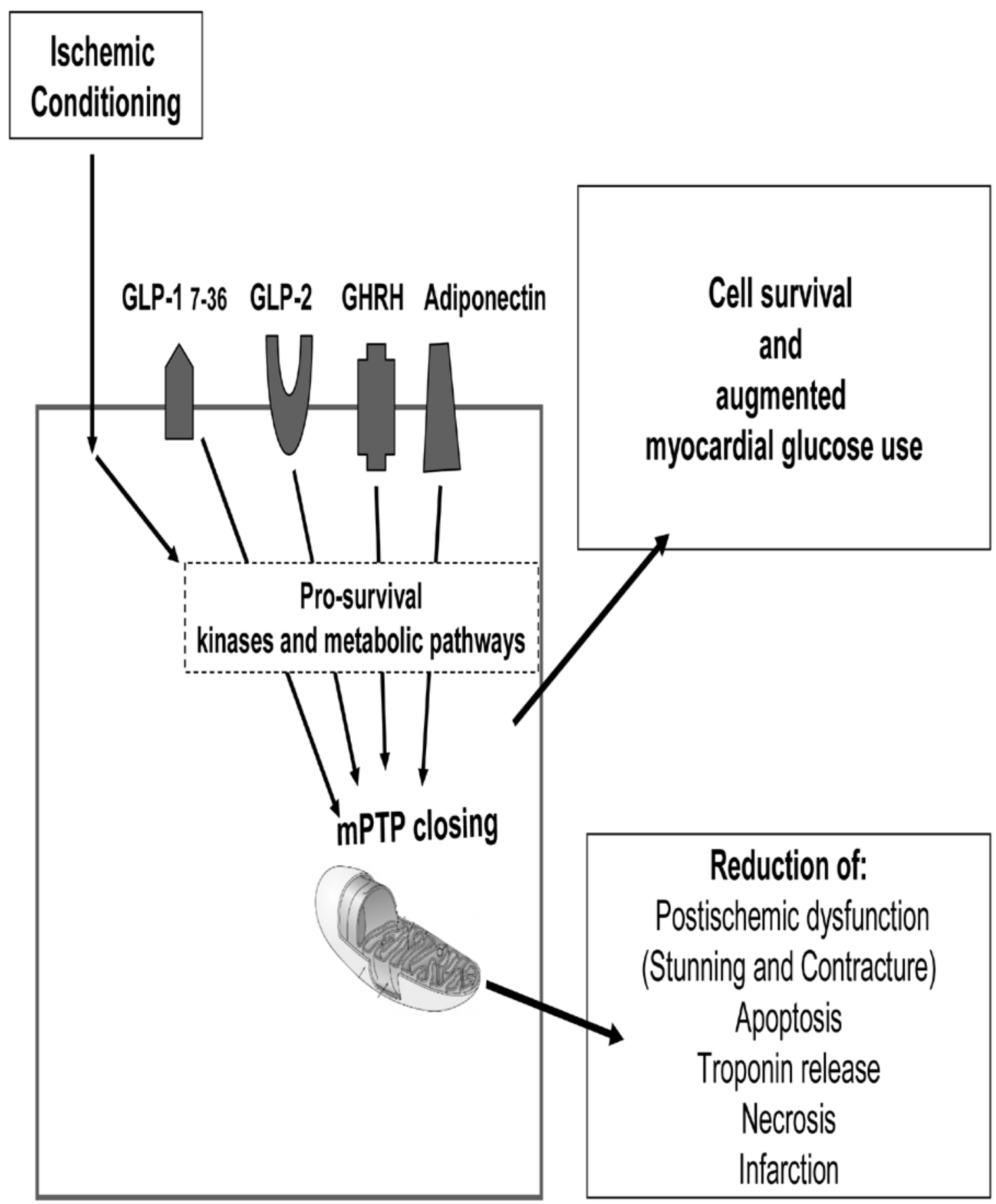




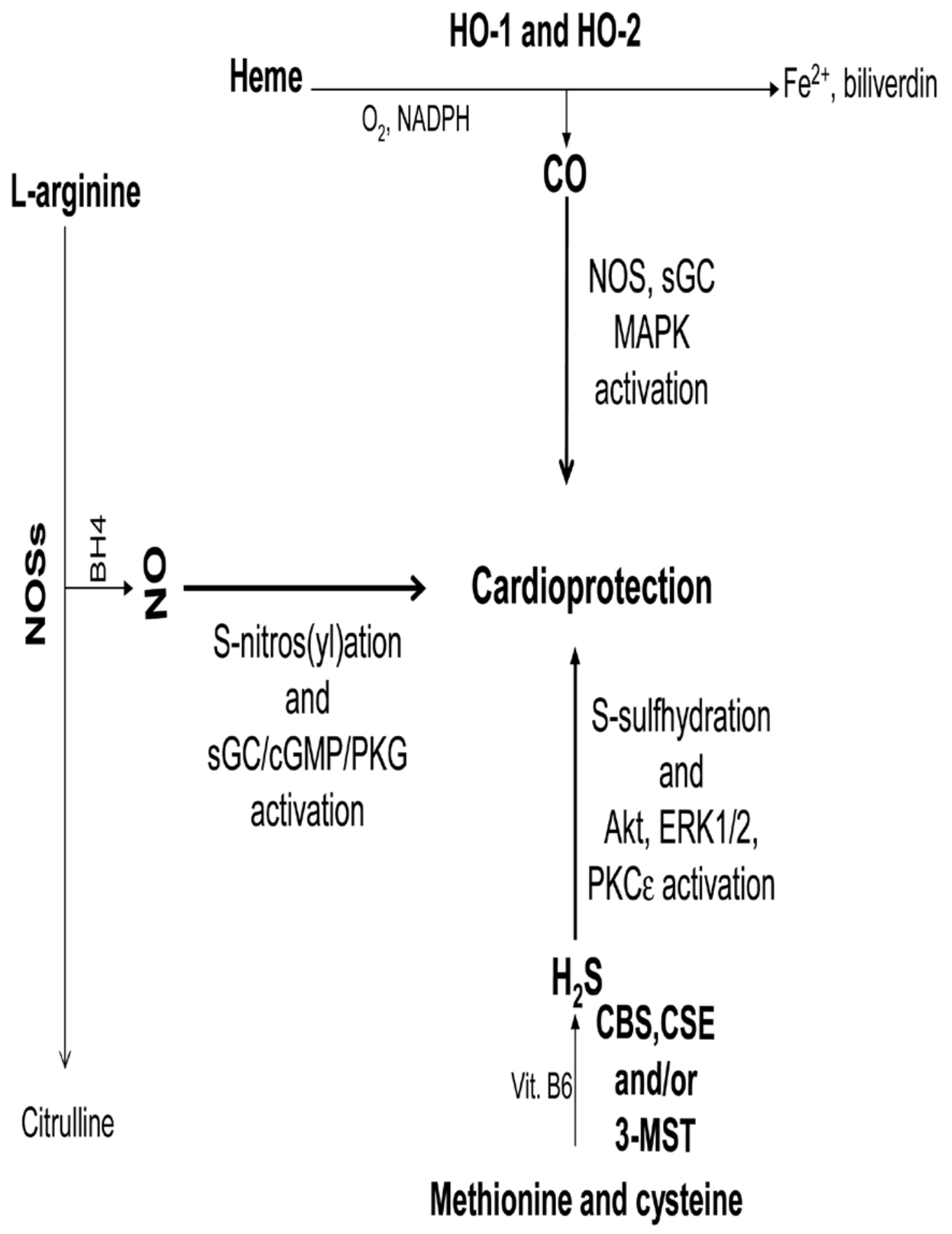




\section{Paracrine/Autocrine Action of Cardioprotective Agents}

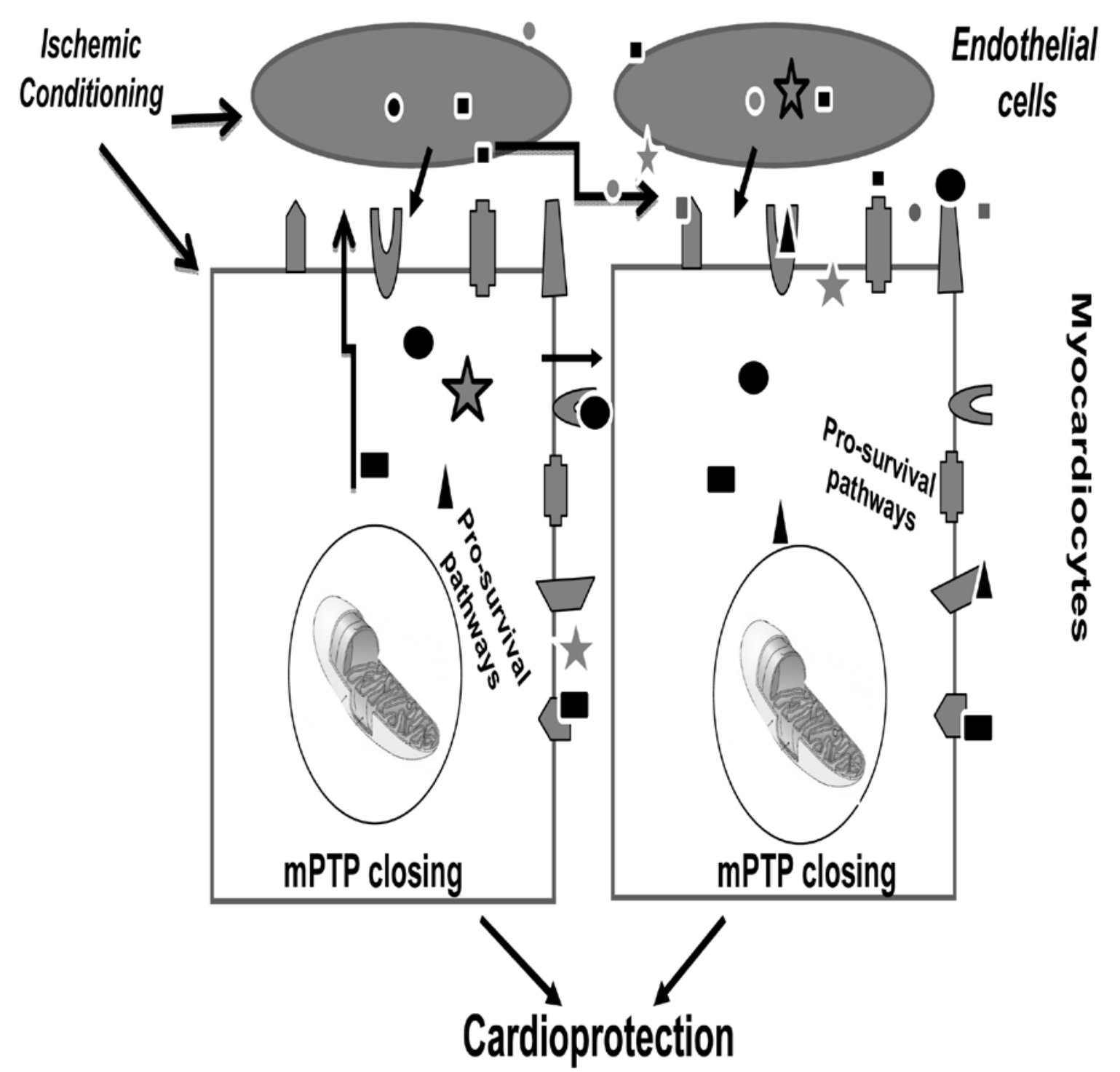

